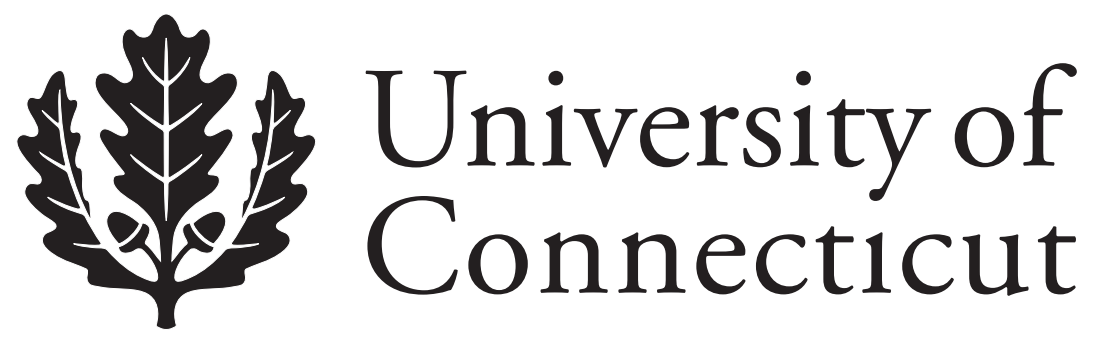

Department of Economics Working Paper Series

\title{
Modeling the Volatility of Real GDP Growth: The Case of Japan
} Revisited

WenShwo Fang

University of Connecticut

Stephen M. Miller

University of Nevada, Las Vegas, and University of Connecticut

Working Paper 2008-47

December 2008

341 Mansfield Road, Unit 1063

Storrs, CT 06269-1063

Phone: (860) 486-3022

Fax: (860) 486-4463

http://www.econ.uconn.edu/

This working paper is indexed on RePEc, http://repec.org/ 


\begin{abstract}
Previous studies (e.g., Hamori, 2000; Ho and Tsui, 2003; Fountas et al., 2004) find high volatility persistence of economic growth rates using generalized autoregressive conditional heteroskedasticity (GARCH) specifications. This paper reexamines the Japanese case, using the same approach and showing that this finding of high volatility persistence reflects the Great Moderation, which features a sharp decline in the variance as well as two falls in the mean of the growth rates identified by Bai and Perrons $(1998,2003)$ multiple structural change test. Our empirical results provide new evidence. First, excess kurtosis drops substantially or disappears in the GARCH or exponential GARCH model that corrects for an additive outlier. Second, using the outlier-corrected data, the integrated GARCH effect or high volatility persistence remains in the specification once we introduce intercept-shift dummies into the mean equation. Third, the time-varying variance falls sharply, only when we incorporate the break in the variance equation. Fourth, the ARCH in mean model finds no effects of our more correct measure of output volatility on output growth or of output growth on its volatility.
\end{abstract}

Journal of Economic Literature Classification: C32, E32, O40

Keywords: Japan, real GDP growth, the Great Moderation, outlier, structural changes, IGARCH effect 


\section{Introduction}

Real GDP growth involves long-run phenomena. For a longer sample period, structural changes in volatility will occur with a higher probability. For example, Kim and Nelson (1999), McConnell and Perez-Quiros (2000), Blanchard and Simon (2001), and Ahmed et al. (2004), among others, document a structural change in the volatility of U.S. GDP growth, finding a rather dramatic reduction in GDP volatility that some have labeled the Great Moderation. Stock and Watson (2003), Bhar and Hamori (2003), Mills and Wang (2003), and Summers (2005) show a structural break in the volatility decline of the output growth rate for Japan and other G7 countries, although the break occurs at different times.

Researchers frequently employ some form of a generalized autoregressive conditional heteroskedasticity $(\mathrm{GARCH})$ modeling strategy to examine the volatility of real GDP growth. Most such studies, however, assume a stable GARCH or exponential GARCH (EGARCH) process capturing the movement in volatility. The neglect of potential structural breaks in the unconditional or conditional variances of output growth leads to high persistence in the conditional volatility or integrated GARCH (IGARCH). For example, Hamori (2000) finds that the GARCH persistence of volatility equals 0.972 for Japan and 0.987 for the U.S. and EGARCH persistence of 1.013 for Japan and 0.968 for the U.S. Ho and Tsui (2003) report that the EGARCH persistence equals -0.4147 for Japan, and equals 0.916 for the U.S. Finally, Fountas et al. (2004) find GARCH and EGARCH volatility persistence of 0.982 and 0.962 , respectively, for Japan. All persistence measures fall close to one except a negative estimate.

The evidence of a structural change in output growth volatility combined with finding high persistence in conditional volatility motivates us to revisit the issue of conditional volatility in real GDP growth rates for Japan. We report that a structural break exists in the variance 
resulting in high volatility persistence. This issue is well known at the theoretical level; ${ }^{1}$ but, the only empirical examination for the U.S. appears in Fang and Miller (2008). This paper contributes to the literature by providing some new evidence from Japan. First, excess kurtosis in the growth rate drops substantially or disappears, once we incorporate an outlier in the GARCH model, either a symmetric or an asymmetric specification. Non-normally distributed residuals may emerge by not modeling the extraordinary change in the growth series. Second, the IGARCH effect or high volatility persistence remains, when we introduce two structural breaks in the mean equation. Third, the time-varying variance falls sharply, only when we incorporate the break in the variance equation. The IGARCH effect proves spurious due to nonstationary variance of output growth. Fourth, the $\mathrm{ARCH}(1)-\mathrm{M}$ model finds no significant effects of our more correct specification of output volatility on output growth or of output growth on its volatility.

Although our paper generally applies to modeling real GDP growth volatility using the GARCH approach, we focus on the Japanese case because it provides an interesting example, particularly when compared with the U.S. Using U.S. quarterly real GDP data, Fang and Miller (2008) report that the long-term growth rate of output keeps unchanged and its variance declines.

\footnotetext{
${ }^{1}$ Diebold (1986) first argues that structural changes may confound persistence estimation in GARCH models. He notes that Engle and Bollerslev's (1986) integrated GARCH (IGARCH) may result from instability of the constant term of the conditional variance (i.e., nonstationarity of the unconditional variance). Neglecting such changes can generate spuriously measured persistence with the sum of the estimated autoregressive parameters of the conditional variance heavily biased towards one. Lamoureux and Lastrapes (1990) provide confirming evidence that ignoring discrete shifts in the unconditional variance, the misspecification of the GARCH model can bias upward GARCH estimates of persistence in variance. Including dummy variables to account for such shifts diminishes the degree of GARCH persistence. More recently, Mikosch and Stărică (2004) prove that the IGARCH model makes sense when non-stationary data reflect changes in the unconditional variance. Hillebrand (2005) shows that in the presence of neglected parameter change-points, even a single deterministic change-point can cause GARCH to measure volatility persistence inappropriately. Alternatively, Hamilton and Susmel (1994) and Kim et al. (1998) suggest that the long-run variance dynamics may include regime shifts, but within a given regime, it may follow a GARCH process. Kim and Nelson (1999), Bhar and Hamori (2003), Mills and Wang (2003), and Summers (2005) apply this approach of Markov switching heteroskedasticity with two states to examine the volatility of real GDP growth and identify structural changes.
} 
This combination may imply immediately a weak relationship between growth and volatility. ${ }^{2}$ In contrast, Japan grew much more rapidly in the 1960s, during postwar reconstruction, than in the past few decades. We show that in Japan structural changes emerge in the variance as well as the mean of the real GDP growth rate identified by the multiple structural change test of Bai and Perron $(1998,2003)$. If the long-term mean growth rate fell substantially, the implication of the Great Moderation for the relationship between output growth and its volatility is not straightforward and requires model-based calculations.

The rest of the paper unfolds as follows. Section 2 discusses the data, detects and corrects outliers, models the unstable GARCH process of output growth volatility, and identifies the break dates in the mean and the conditional variance. Section 3 presents empirical results with changes in the mean and the variance and identifies two areas of misspecification of the GARCH modeling of output growth volatility. Section 4 considers evidence on the relationship between the output growth rate and its volatility. Finally, Section 5 concludes.

\section{Data and Unstable GARCH process}

Output growth rates $\left(y_{t}\right)$ equal the percentage change in the logarithm of seasonally adjusted quarterly real GDP $\left(Y_{t}\right)$ with base year 2000 over the period 1955:2 to 2008:2. All data come from http://www.esri.cao.go.jp/en/sna/data.html, the Cabinet Office, Government of Japan. The original source contains three quarterly estimates of GDP: the 1990 benchmark year for official series 1955:2 to 1979:4 and reference series 1980:1 to 2001:1, the 1995 benchmark year for official series 1980:1 to $1993: 4$ and reference series $1994: 1$ to $2005: 2$, and the 2000 benchmark year for 1994:1 to 2008:2. Accordingly, three quarterly raw data series underlie the quarterly series used in this paper. That is, we create the quarterly real GDP series, involving two splices.

\footnotetext{
${ }^{2}$ Stock and Watson (2003) interpret the moderation in output volatility with no change in the mean growth rate as shorter recessions and longer expansions in the U.S.
} 
First, we splice the 1955:2 to 1980:1 real GDP series to the 1980:1 to 1994:1 real GDP series, measured in 1995 prices. The government measures the first historical real GDP series in 1990 prices, which we convert to 1995 prices by multiplying by 1.043 (equals the ratio of the 1995 currency value to 1990 currency value in the overlap quarter 1980:1). ${ }^{3}$ Second, we splice the resulting spliced series from 1955:2 to $1994: 1$ series to the $1994: 1$ to $2008: 2$ series by converting to 2000 prices by multiplying by 0.970 (equals the ratio of the 2000 currency value to 1995 currency value in the overlap quarter 1994:1).

Table 1 reports descriptive statistics for the growth rate of the spliced quarterly real GDP. Japan experiences a mean growth rate of 1.1667 percent for the full 54-year sample with the highest rate of 6.8306 in $1960: 1$ and the lowest rate of -3.4964 in 1974:1. Output volatility, represented by the standard deviation, equals 1.3037 . Under the assumptions of normality, standard measures of skewness and kurtosis possess asymptotic distributions of $\mathrm{N}(0,6 / \mathrm{T})$ and $\mathrm{N}(0,24 / \mathrm{T})$, respectively, where $\mathrm{T}(=212)$ equals the sample size. The skewness statistic displays an asymmetric distribution. The asymmetry characterized by positive skewness means that in the sample period, a greater probability exists of large increases in real GDP growth than larger decreases. The kurtosis statistic exhibits leptokurticity with fat tails. A higher kurtosis means that extreme changes occur more frequently. The Jarque-Bera test rejects normality. Ljung-Box Q statistic tests for autocorrelation up to seven lags. The Ljung-Box statistics ( $L B Q$ ) indicate autocorrelation in the growth rates. The Ljung-Box statistics for squared rates $\left(L B Q^{2}\right)$ suggest time-varying variance in the series. Autocorrelation and heteroskedasticity suggest ARMA processes for the mean and the variance equations to capture the dynamic structure and to generate white-noise residuals.

\footnotetext{
${ }^{3}$ Diebold and Senhadji (1996) use this method to splice the 1869 to 1929 real GNP series in 1982 dollars to the 1929 to 1993 real GNP series in 1987 dollars.
} 
We construct an AR model for the growth rate series. Based on the Schwarz Bayesian Criterion (SBC), AR(3) process proves adequate to capture growth dynamics and produces uncorrelated residuals. ${ }^{4}$ That is, the mean growth rate equation equals the following:

$$
y_{t}=a_{0}+\sum_{i=1}^{3} a_{i} y_{t-i}+\varepsilon_{t}
$$

where the growth rate $y_{t} \equiv 100 \times\left(\ln Y_{t}-\ln Y_{t-1}\right), \ln Y_{t}$ equals the natural logarithm of real GDP, ${ }^{5}$ and $\varepsilon_{t}$ equals the serially uncorrelated error term.

Hamori (2000), Ho and Tsui (2003), and Fountas et al. (2004) apply symmetric and asymmetric $\operatorname{GARCH}(1,1)$ models to parameterize the time-varying conditional variance of output growth for Japan. Following these authors, this paper uses the same approach modeling volatility process as follows:

$$
\varepsilon_{t}=\sigma_{t} \eta_{t}, \quad \sigma_{t}^{2}=\alpha_{0}+\alpha_{1} \varepsilon_{t-1}^{2}+\beta_{1} \sigma_{t-1}^{2}
$$

where $\eta_{t}$ equals an independent and identically distributed (iid) random variable with mean zero and variance 1 . In addition, $\sigma_{t}^{2}$ equals the conditional variance of the growth rate, given information available at time t-1. The conditions that $\alpha_{i} \geq 0, \beta_{i} \geq 0$, and $\alpha_{1}+\beta_{1}<1$ ensure positive and stable conditional variances of $\varepsilon_{t}$. The sum, $\alpha_{1}+\beta_{1}$, measures the persistence of shocks to the conditional variances. Evidence of an IGARCH, or, in general, evidence of high persistence may result from occasional level shifts in volatility. If $\beta_{1}$ equals zero, the process reduces to an $\operatorname{ARCH}(1)$. When $\alpha_{1}$ and $\beta_{1}$ both equal zero, the variance equals a constant. We estimate the model employing Bollerslev and Wooldridge's (1992) quasi-maximum likelihood

\footnotetext{
${ }^{4}$ In their GARCH models, Hamori (2000) uses AR(2) and AR(4) processes for the conditional mean, while Ho and Tsui (2003) and Fountas et al. (2004) use AR(3) filters. In this study, the SBC chooses AR(3) for our longer sample period.

${ }^{5}$ After selecting lag lengths by the SBC, the augmented Dickey-Fuller (ADF) statistic $(=-4.0061)$ indicates that the growth rates exhibit a stationary $[\mathrm{I}(0)]$ process at the 5-percent level.
} 
estimation (QMLE) technique, assuming normally distributed errors and using the Berndt et al. (1974) (BHHH) algorithm.

The model contained in equations (1) and (2) assumes that positive and negative shocks generate the same effect on volatility, implying a symmetric GARCH specification. The volatility may respond differently to shocks during periods of a rise or a fall in output growth. For example, using the EGARCH model introduced by Nelson (1991), Ho and Tsui (2003) find evidence of asymmetric volatility in the real GDP growth rates of the U.S. and Canada, although these authors, Hamori (2000), and Fountas et al. (2004) all report no evidence of asymmetry in Japan. Verhoeven and McAleer (2004) argue that asymmetry may arise with skewed unconditional returns. Table 1 reports skewness of the growth rates. Thus, to provide a more systematic analysis for our longer sample period, we also examine the following EGARCH process:

$$
\log \sigma_{t}^{2}=\alpha_{0}+\alpha_{1} \frac{\left|\varepsilon_{t-1}\right|}{\sigma_{t-1}}+\alpha_{2} \frac{\varepsilon_{t-1}}{\sigma_{t-1}}+\beta_{1} \log \sigma_{t-1}^{2},
$$

where asymmetry exists if $\alpha_{2} \neq 0$, and when $\alpha_{2}<0$, it implies that negative shocks generate higher volatility than positive shocks of the same magnitude, and vice versa. The coefficient $\beta_{1}$ captures the persistence of shocks in the conditional variance and the log transformation guarantees a positive variance.

Table 2 reports estimation results of the two models with standard errors in parentheses, statistics for the standardized residuals, and p-values in brackets. In Panel A, for the $\operatorname{GARCH}(1,1)$ model, higher-order AR estimates in the mean equation prove significant at the 5percent level, lending support to the autoregressive specification. Each estimate in the variance equation exceeds zero. The volatility persistence measure of 0.9561 matches the high values reported in Hamori (2000) and Fountas et al. (2004) for Japan. The likelihood ratio (LR) tests for 
$\alpha_{1}+\beta_{1}=1$ in the GARCH process do not reject the null hypothesis of an IGARCH effect. The fitted model adequately captures the time-series properties of the data in that the Ljung-Box Qstatistics for standardized residuals and standardized squared residuals, up to 7 lags, do not detect autocorrelation and conditional heteroskedasticity. The standardized residuals, however, exhibit significant excess kurtosis and, thus, do not exhibit a normal distribution at the 5-percent level. In Panel B, for the EGARCH(1,1) model, the insignificant estimate of $\alpha_{2}$ suggests that good news and bad news do not exert different effects on output growth volatility. All properties of the diagnostic statistics, such as no autocorrelation and heteroskedasticity, significant kurtosis and normality test, and the insignificant LR test match those exhibited in the GARCH model. The significant IGARCH effect ( $\beta_{1}=0.9393$ ) appears in Hamori (2000) and Fountas et al. (2004).

The empirical results of the GARCH models may reflect model misspecification in, at least, two ways. First, on the one hand, Stock and Watson (2003), Bhar and Hamori (2003), Mills and Wang (2003), and Summers (2005) document the decline in volatility of Japan's output growth. On the other hand, Diebold (1986), Lamoureux and Lastrapes (1990), Mikosch and Stărică (2004), and Hillebrand (2005) note theoretically that Engle and Bollerslev's (1986) IGARCH may result from instability of the constant term in the conditional variance (i.e., nonstationarity of the unconditional variance). Neglecting such changes can generate spuriously measured persistence of the conditional variance heavily biased towards one. Thus, the high volatility persistence found in the GARCH models in Table 2 may prove spurious, since we do not incorporate structural change in the variance. That the empirical results may depend on whether the researcher models the structural changes in the variance does not break new ground. See Lastrapes (1989), Tzavalis and Wickens (1995), and Fang and Miller (2008) for an analysis in the GARCH framework, and the references contained in these studies for different 
applications. While this issue receives some attention for the U.S., no analysis of this issue considers the Japanese case. As noted by Blanchard and Simon (2001) and Stock and Watson (2003), Japan's patterns of output growth and its volatility differ from that of the other G7 countries. Therefore, Japan deserves more analysis of the conditional volatility of its real GDP growth. Specifically, it experiences two declines in its growth rate in addition to its volatility. Krämer and Azamo (2007) show that changes in the mean equation may explain changes in the volatility.

Second, according to the distributional assumption in the GARCH specifications, the standardized residuals should reflect a normal distribution, if the GARCH models totally capture unconditional skewness and leptokurtic distributions. The sample skewness and kurtosis in Table 2 for the standardized residuals indicate that the GARCH solves the skewness but only some of leptokurtosis for the output growth rate. Thus, the significant statistics of kurtosis and the JarqueBera normality test provide another cautionary note. Blanchard and Simon (2001) note that the distribution of output growth exhibits excess kurtosis, if large and infrequent shocks occur. This suggests that the evidence of kurtosis may reflect extreme changes in the mean growth rate. We argue that not considering such changes as outliers, structural breaks in the mean, or structural breaks in the variance of the growth rate may leave the excess kurtosis unresolved, as seen in Table 2.

Thus, we expect to resolve these two issues of misspecification by modeling outliers and changes in the mean and the variance equations. That is, the likelihood of biasing the estimated volatility persistence parameters toward one and the skewness and leptokurtosis in the distribution of output growth vanishes after adjustment of the GARCH model with various changes. 
Economic and financial time series frequently include outliers. ${ }^{6}$ An outlier observation appears inconsistent with other observations in the growth rates. To the best of our knowledge, however, researchers typically overlook their existence and effect when modeling output growth volatility. For example, Fang and Miller (2008) apply Inclán and Tiao’s (1994) iterated cumulative sum of squares (ICSS) algorithm to detect structural changes in the variance, neglecting the effects of sample contamination of outliers. Rogrigues and Rubia (2007) prove that the asymptotic distribution of the ICSS test varies under additive outliers. The critical values from this distribution generally prove inadequate for the test, which finds too many breaks. Moreover, the situation worsens with time-varying volatility. In the context of persistent volatility patterns and additive outliers, the test is severely distorted and is expected to provide unreliable inference no matter the available number of observations.

In Table 2, excess kurtosis in the GARCH residuals implies the presence of outliers in the growth series that the GARCH models do not capture (Balke and Fomby, 1994; Franses and Ghijsels, 1999; Charles and Darné, 2005, 2006; and Bali and Guirguis, 2007). In addition, the high persistence measures may reflect structural changes in the mean or variance of growth rates, which the GARCH estimations ignore (Diebold, 1986; Lamoureux and Lastrapes, 1990; Mikosch and Stărică, 2004; Hillebrand, 2005; Krämer and Azamo, 2007; and Fang and Miller, 2008). Following Franses and Ghijsels (1999) and Charles and Darné (2005), we, first, employ the method of Chen and Liu (1993) to detect and correct for additive outliers (AOs) and

\footnotetext{
${ }^{6}$ Balke and Fomby (1994) analyze fifteen post-World War II U.S. macroeconomic time series using the outlier identification procedure based on Tsay (1988) and find that outliers may prove important for U.S. macroeconomic data, and such aberrant observations may lead to large ARCH test statistics. van Dijk, Franses, and Lucas (1999) demonstrate that neglecting additive outliers frequently leads to a rejection of the null hypothesis of homoskedasticity, when it is in fact true. Tolvi (2001) and Charles and Darné (2006), however, show another possibility. That is, outliers can hide the ARCH tests of the series. After correcting the data for outliers, returns series sometimes display strong evidence of ARCH. Franses and Ghijsels (1999) and Charles and Darné (2005, 2006) apply the method of Chen and Liu (1993) to correct for additive outlier and show that correcting for additive outliers reduces excess kurtosis in GARCH models and improves forecasts of stock market volatility.
} 
innovative outliers (IOs), if any, in the GARCH models. Using the outlier-corrected GDP growth series and following Cecchetti et al. (2005) and Herrera and Pesavento (2005), we, second, apply the multiple structural change test of Bai and Perron $(1998,2003)$ to detect structural changes in the mean and the variance of the series.

Franses and Ghijsels (1999) and Charles and Darné (2005) develop a method to detect and correct additive and innovative outliers in GARCH models based on the outlier detection procedure by Chen and Liu (1993). An AO, an exogenous change, affects the level of the series when the outlier occurs. An IO, an endogenous change, affects the series after it occurs through the memory of the process. In the detection process, we, first, estimate the $\operatorname{GARCH}(1,1)$ model for the growth rate series and obtain estimates of the conditional variance, $\sigma_{t}^{2}$, which we write as an ARMA(1,1) model for $\varepsilon_{t}^{2}$ (see Bollerslev, 1986) and that may involve contamination from AOs and/or IOs. We, then, compute the test statistics (see Franses and Ghijsels (1999), Peña (2001), and Charles and Darné (2005) for details). An outlier exists when the maximized statistic among all possible observations exceeds the prespecified critical value, which equals ten (10) in our application. The choice for a critical value reflects simulation experiments proposed by Franses and van Dijk (2004, pp.181-182). We, next, replace the observed growth rates with outlier-corrected values, depending on AOs and/or IOs. Finally, we estimate the GARCH model for the outlier-corrected growth rates and repeat all steps until no maximized test statistic exceed the critical value. ${ }^{7}$

We find two outliers, an additive outlier and an innovative outlier, both at the same date 1974:1. According to Chen and Liu (1993), at the date, the larger is the test statistic, the more likely is the type of outlier. We, therefore, treat the outlier as an AO, since it exhibits the largest

\footnotetext{
${ }^{7}$ We detect and correct outliers in the series of output growth using the GAUSS code available from Dick van Dijk's web page at http://people.few/eur.nl/djvandijk/nltsmef/nltsmef.htm.
} 
test statistic. Table 3 reports descriptive statistics for the outlier-corrected growth rate. Compare Table 3 to Table 1. Since the AO at 1974:1 is the minimum observation (-3.4964 in Table 1), this correction leads to higher mean value and skewness in Table 3. The statistics of kurtosis and the normality test fall, but both remain significant. In econometrics, we expect the standardized residuals to exhibit a normal distribution after GARCH adjustment. Table 4 reports that, using the outlier-corrected GDP growth series, the insignificant statistics of the Jarque-Bera test suggest normally-distributed residuals, although the kurtosis proves marginally significant at the 10-percent level in the GARCH(1,1) model. All other estimates and statistics match those in Table 2 except that $\alpha_{2}$ now proves significant. Asymmetry appears sensitive to the data, reflecting the higher skewness after outlier correction. The IGARCH effect remains, however, in both the GARCH and the EGARCH models, as evidenced by the insignificant LR statistics.

Using the outlier-corrected data, we look for structural changes in the volatility for GDP growth in sequential steps. First, we estimate equation (1) allowing for the possibility of structural breaks in its intercept. Specifically, we use the statistical techniques of Bai and Perron $(1998,2003)$ to estimate multiple break dates without prior knowledge of when those breaks occur. After finding any breaks in the mean of $y_{t}$, we use that model specification to obtain series of estimated residuals, $\hat{\varepsilon}_{t}$. Second, we search for breaks in the variance by testing for parameter constancy in the conditional mean of the absolute value of the residuals $\hat{\varepsilon}_{t}$ as shown in Cecchetti et al. (2005) and Herrera and Pesavento (2005).

Bai and Perron $(1998,2003)$ propose several tests for multiple breaks. We adopt one procedure and sequentially test the hypothesis of $\mathrm{m}$ breaks versus $\mathrm{m}+1$ breaks using $\sup F(m+1 \mid m)$ statistics, which detects the presence of $m+1$ breaks conditional on finding $m$ breaks and the supremum comes from all possible partitions of the data for the number of breaks 
tested. In the application of the test, we search for up to five breaks. If we reject the null of no break at the 5-percent significance level, we, then, estimate the break date using least squares, to divide the sample into two subsamples according to the estimated break date, and to perform a test of parameter constancy for both subsamples. We repeat this process by sequentially increasing $m$ until we fail to reject the hypothesis of no additional structural change. In the process, rejecting $m$ breaks favors a model with $m+1$ breaks, if the overall minimal value of the sum of squared residuals over all the segments, including an additional break, falls sufficiently below the sum of squared residuals from the model with $m$ breaks. The break dates selected include the ones associated with this overall minimum. We search for multiple breaks in the series of output growth using the GAUSS code made available by Bai and Perron (2003).

Table 5 displays the results of testing for breaks in the mean and the variance, their critical values at the 5-percent significance level (in parentheses), and structural stability test. In Panel A, the value of the $\sup F(5 \mid 0)$ test proves significant for $m=5$, suggesting the existence of at least one break in the growth rate series. The sequential $\sup F(m+1 \mid m)$ exhibits significance up to $m=2$. That is, given the existence of one break, $\sup F(21)=18.6595$ suggests that a second break exists. The next test, $\sup F(3 \mid 2)=1.4464$ falls below the critical value, suggesting that only two breaks exist in the mean growth series. The break dates occur at 1973:1 and 1991:1, respectively. Using the same approach, but assuming a simple $A R(1)$ model and testing for multiple breaks in the persistence coefficient (i.e., only $a_{i}$ in equation 1), Cecchetti et al. (2005) find no breaks for Japan. ${ }^{8}$ Our results more closely approximate the break date in Stock and

\footnotetext{
${ }^{8}$ Applying the Bai and Perron's test to both the constant term and the AR persistence parameters in the mean equation 1 yields the same break dates at 1973:1 and 1991:1. Since not one of the six AR persistence dummies is significant, we conclude that the source of changes in the mean comes from the intercept. That is, in this application, it does not matter whether we consider the break points in the constant term alone or all parameters simultaneously.
} 
Watson (2005), who use $A R(4)$ models over the period 1960:1 to 2002:4 and find one break at 1973:1. We identify two breaks in our longer sample period.

In Panel B, the procedure identifies a single structural break in the variance of growth rates at 1972:1. Thus, change in the GARCH process governs volatility. Stock and Watson (2003) estimate instantaneous standard deviations of four-quarter GDP growth and show that the volatility of real GDP fell in the 1970s. Mills and Wang (2003) fit Hamilton's Markov chain model to post-war quarterly output growth that allows for a one-time structural break and find the break around 1976. Summers (2005) uses the Markov switching model with high and low GDP volatility regimes for quarterly data and reports the date of the switch from high to low volatility as 1975:2. Cecchetti et al. (2005), use shorter quarterly data of real GDP growth starting in 1970, finding no break. Different approaches find different break dates. Generally, the evidence indicates that the Japanese break date occurs some time in the early to mid 1970s, nearly 10-year earlier than the U.S. break date of 1984:1 in McConnell and Perez-Quiros (2000) and 1982:1 in Fang and Miller (2008).

In Table 5, Panels $\mathrm{C}$ and $\mathrm{D}$, we further conduct structural stability tests for the unconditional variance as well as the mean of the growth rate by splitting the sample into subperiods according to the break date. For the unconditional mean, a t-statistic tests for the equality of means under unequal variances for two different samples, while a variance-ratio statistic tests for the equality of the unconditional variances.

In Panel $\mathrm{C}$, the mean growth rates in each sub-sample differ significantly, since the tstatistic rejects the null hypothesis of equal means. Japan experiences a significant drop in the mean growth from 2.2615 in the pre-1973 sample period to 1.0684 in the period between 1973 to 1991, and a further drop to 0.2951 in the post-1991 period. The decline in the mean growth rate This also confirms Cecchetti et al. (2005) finding of no breaks in the AR terms in equation 1. 
equals 87-percent from the pre-1973 to the post-1991 period. In Panel D, also a clear decline in the standard deviation of the growth rate occurs from 1.3573 in the pre-1972 sample to 0.8805 in the post-1972 sample. The p-values for the variance-ratio F-test significantly reject the null of variance equality between the two samples. The decline equals 35 -percent in the variance. As the introduction notes, economists call the substantial drop in the variance of output growth in the period after the break the Great Moderation.

Figure 1 plots observed real GDP, its growth rate, and marks the outliers, the break dates for the mean as well as the variance with a grey area, where horizontal lines denote the mean growth rates in the three regimes, respectively.

Fang and Miller (2008) report that U.S. output volatility declines 49-percent with no change of the mean growth rate in the post-break sub-period over the period 1947:1 to 2006:2. Thus, two important differences of preliminary statistics for quarterly real GDP growth emerge between Japan and the U.S. First, the Great Moderation in the U.S. means moderation in output volatility. In Japan, the Great Moderation means two declines in the mean growth rate in addition to a decline in the variance. Second, and most interestingly, Japan and the U.S. experience a tenyear gap between their break dates, but both exhibit a high degree of moderation in variance. Most research investigates the causes of the Great Moderation such as good policies, structural change, good luck, or output composition shifts, as discussed in McConnell and Perez-Quiros (2000), Blanchard and Simon (2001), Stock and Watson (2003), Ahmed et al. (2004), Bernanke (2004), Summers (2005), Eggers and Ioannides (2006), and Fang and Miller (2008), focusing on the economy of the U.S. To date, no agreement exists on the cause or causes of the reduced volatility. This rest of this paper addresses the effect of the Great Moderation on the time-series 
specification of output growth volatility in GARCH models as well as the effects, if any, of our output growth volatility measure on output growth and of output growth on its volatility in Japan.

\section{Structural Changes and GARCH Estimates}

To consider the effect of the Great Moderation on the volatility persistence of output growth in GARCH specifications, we include a dummy variable in the conditional variance equation, which equals unity from the break date forward, zero otherwise, in the GARCH and EGARCH processes, respectively, as follows:

$$
\begin{aligned}
& \sigma_{t}^{2}=\alpha_{0}+\alpha_{1} \varepsilon_{t-1}^{2}+\beta_{1} \sigma_{t-1}^{2}+\gamma D, \\
& \log \sigma_{t}^{2}=\alpha_{0}+\alpha_{1} \frac{\left|\varepsilon_{t-1}\right|}{\sigma_{t-1}}+\alpha_{2} \frac{\varepsilon_{t-1}}{\sigma_{t-1}}+\beta_{1} \log \sigma_{t-1}^{2}+\gamma D,
\end{aligned}
$$

where $D=1$ for $t>1972: 1$; and 0 , otherwise. The dummy variable accommodates the extraordinary change. Since the volatility declines, we expect a significant negative estimate of $\gamma$ to capture the break in the variance process.

Japan also experiences two sharp drops in its growth rates in addition to the moderation in its volatility at the break dates 1973:1 and 1991:1. To capture the mean shifts, two dummy variables, defined as $D_{1}=1$ for $t>1973: 1$, zero otherwise, and $D_{2}=1$ for $t>1991: 1$, zero otherwise, enters into the mean equation as follows:

$$
y_{t}=a_{0}+\sum_{i-1}^{3} a_{i} y_{t-i}+d_{1} D_{1}+d_{2} D_{2}+\varepsilon_{t},
$$

To see the effect of the mean changes, Table 6 reports the estimation results, where we include these two dummy variables in the mean equation, but still exclude the shift dummy variable from the variance equation. For each of the two GARCH models, the coefficients of the two mean-shift dummies $\left(d_{1}\right.$ and $d_{2}$ ) prove highly significant with no autocorrelation or heteroskedasticity. Excess kurtosis leads to non-normally distributed errors and high volatility 
persistence remains. The insignificant LR statistic does not reject the null hypothesis of $\alpha_{1}+\beta_{1}=1$ in the GARCH, the LR test rejects $\beta_{1}=1$ at the 10-percent level in the EGARCH, and the $\beta_{1}=0.9272$ proves significant and high. Generally, the mean shifts cannot adequately explain high volatility persistence in either the symmetric or the asymmetric model. This result reinforces Sensier and van Dijk's (2004) finding that allowing for a structural change in the mean equation does not affect the distribution of percentage changes in standard deviation, but does not support Krämer and Azamo’s (2007) argument.

Table 7 reports the estimates with both the mean and variance dummy variables. The coefficient of the structural dummy (i.e., $\gamma$ ) proves significantly negative at least at the 10percent level in the variance equation along with significant dummies in the mean equation (i.e., $d_{1}$ and $d_{2}$ ). The improvement of the value of the maximum log-likelihood (see Tables 2, 4, 6, and 7) indicates that including all three dummy variables in the GARCH models provides a better performance. The Ljung-Box Q-statistics of the standardized residuals and the squared standardized residuals show no evidence of autocorrelation and heteroskedasticity, providing support for the specification of the GARCH or the EGARCH. The significant LR statistic at the 5-percent level indicates no IGARCH effect. In fact, for the GARCH $(1,1)$ model, not only does a large decline occur in the estimated degree of persistence in the conditional variance, but also the estimate of $\beta_{1}$ becomes insignificant in the specification that includes the dummy variable. That is, the $\operatorname{GARCH}(1,1)$ model reduces to an $\mathrm{ARCH}(1)$. Panel $\mathrm{B}$ reports a parsimonious $\operatorname{ARCH}(1)$ model with the three insignificant estimates (i.e., $a_{1}, a_{2}$, and $\beta_{1}$ ) deleted. The insignificant likelihood ratio statistic $(=1.0284)$, testing for the deletion and distributed as a $\chi^{2}$ with 3 degrees of freedom, suggests that the simple $\mathrm{ARCH}(1)$ model possesses the same explanatory power as the $\operatorname{GARCH}(1,1)$ model. All estimates and statistics match those in Panel 
A except that $\alpha_{1}$ no longer proves significant, reducing the $\mathrm{ARCH}(1)$ to a constant. For the $\operatorname{EGARCH}(1,1)$ model in Panel $\mathrm{C}$, the persistence measure $\beta_{1}$ reduces to 0.2604 and proves insignificant. The estimate of asymmetry, $\alpha_{2}$, is significant at the 10-percent level. For all three specifications, the coefficients of skewness and excess kurtosis prove insignificant. The standardized residuals conform to a normal distribution.

In sum, the results of the symmetric or asymmetric GARCH models suggest that the high time-varying variance in the growth rate may reflect the change in the variance caused by the Great Moderation.

Previous studies that employed a $\operatorname{GARCH}(1,1)$ modeling approach investigating volatility of real GDP growth generally conclude that high volatility persistence in the real growth rates exists in Japan. This study revisits this issue and finds no high volatility persistence. Although our quarterly real GDP data, spanning 1955:2 to 2008:2, contain more recent data than the sample from 1960:1 to 1996:4 in Hamori (2000), from 1961:1 to 1997:4 in Ho and Tsui (2003), or from 1961:1 to 2000:2 in Fountas et al. (2004), do sample period differences explain differences in the empirical findings? Or do differences in findings relate to structural changes in the variance of the growth rate in each of the sample periods? To consider the robustness of our results, we examine outliers and changes in the mean and the variance for these samples.

For comparison purpose, we now employ the original Japanese quarterly estimates of GDP with base year 1990 over the period 1955:2 to 2001:1. The descriptive statistics show autocorrelation, heteroskedasticity, and leptokurtosis for all three sample periods. To save space, we do not report detailed statistics. The SBC selects an AR(3) filter, the same process used by Ho and Tsui (2003) and Fountas et al. (2004), for each of the three samples. Different samples may experience different dates of outliers and breaks, although we do not expect dramatic 
changes in such dates. The Franses and Ghijsels' (1999) procedures find a single additive outlier at 1974:1, the same date of the outlier in our longer sample period, for each of the three shorter periods. Using the outlier-corrected growth rate, the Bai and Perron's $(1998,2003)$ algorithm detects a significant fall in the mean at 1973:1 and a significant decline in the variance at 1972:1 for the sample period 1960:1 to 1996:4, and two falls at 1973:2 and 1991:1 in the mean and a decline at 1975:3 in the variance for the period 1961:1 to 1997:4, and at 1973:1 and 1990:4 in the mean and 1975:1 in the variance for 1961:1 to $2000: 2$. These contrast to the break dates at 1973:1 and 1991:1 for the mean and 1972:1 for the variance found earlier in our sample period 1955:2 to 2008:2. All breaks occur at almost the same dates except the second and the third variance change of 1975, which occurs three-year later than the change of 1972 in the first and our full sample. ${ }^{9}$

Following the same procedures used before, we see IGARCH estimates and significant kurtosis with no autocorrelation and heteroskedasticity for each of the three samples, when we ignore changes in the data (i.e., outliers and changes in mean and variance), the same evidence as reported in Table 2. When we use the outlier-corrected data and observe the effect of including breaks in the mean equation for each sample, the mean-shift dummies $\left(d_{1}\right.$ and $\left.d_{2}\right)$ prove significantly negative with no autocorrelation and heteroskedasticity. Insignificant skewness and kurtosis, and, thus, normally distributed residuals emerge in two EGARCH estimations. The high volatility persistence of an IGARCH appears in all six symmetric and asymmetric specifications. Table 8 reports these findings.

\footnotetext{
${ }^{9}$ We examine descriptive statistics for the data in the pre- and post-break subsamples for the three sample periods. The same conclusions emerge as in our sample period (see Table 5). The t-statistic rejects the null of equality of means between samples and the variance ratio rejects the null of variance equality between samples. To save space, we do not report detailed statistics, which are available on request.
} 
Finally, when we incorporate the dummy variables in both the mean and variance equations, volatility persistence declines. Table 9 reports the estimation results for each of the

three periods. For the two models, the significant negative estimates of $d_{1}, d_{2}$, and $\gamma$ reflect the extraordinary declines in the mean and the variance processes. Diagnostic statistics show no autocorrelation, heteroskedasticity, skewness, and kurtosis at the 5-percent level. The JarqueBera test suggests that each series of the residuals displays normally distributed errors. Both the GARCH and the EGARCH models are adequately specified. Volatility persistence declines in that the significant LR statistic indicates no IGARCH effect in each of the three periods. Interestingly, the EGARCH estimates a negative estimate of $\beta_{1}$, which also appears in Hamori (2000) and Ho and Tsui (2003). One explanation is that the estimate $\alpha_{2}$ is insignificant, suggesting no need for an asymmetric specification. The same conclusion occurs in Hamori (2000), Ho and Tsui (2003), and Fountas et al. (2004).

In sum, previous studies assume implicitly that a stable GARCH process governs conditional growth volatility. The neglect of the structural break in the variance implies misspecification of the conditional variance. This leads to the conclusion of a significant IGARCH effect as in the GARCH and EGARCH estimations of Hamori (2000) and Fountas et al. (2004). Moreover, taking no account possible outliers and breaks in the growth rates entails excess kurtosis, and, thus, a significant Jarque-Bera test as reported by Ho and Tsui (2003), violating the normality assumption and generating another issue of misspecification for the GARCH model.

\section{Relationship between Output Volatility and Economic Growth}

The prior section considers the appropriate time-series specification of the volatility of the growth rate of real GDP. A number of authors examine the issue of how this volatility affects the 
growth rate of GDP. That is, does the decreased real GDP growth rate volatility cause a higher or lower real GDP growth rate? For example, applying a GARCH in mean (GARCH-M) model (Engle et al., 1987) and using post-war real quarterly GDP data, Henry and Olekalns (2002) discover a significant asymmetric GARCH effect and a negative link between volatility and real GDP growth for the U.S. without consideration of structural shift in the volatility process. In contrast, Fang and Miller (2008) find a weak GARCH effect and no link between volatility and growth for the U.S. with a structural break in the volatility process. Fountas et al. (2004) analyze Japan's data and conclude that output volatility does not affect output growth under the assumption of a stable GARCH process. This section pursues this question with our more appropriate time-series specification of the real GDP growth rate volatility. This issue is important because structural break in variance biases upward GARCH estimates of persistence in variance and, thus, vitiates the use of GARCH to estimate its mean effect.

In this section, the mean growth rate shown in equation (6) translates into the following:

$$
y_{t}=a_{0}+\sum_{i-1}^{3} a_{i} y_{t-i}+\lambda \sigma_{t}+d_{1} D_{1}+d_{2} D_{2}+\varepsilon_{t},
$$

where $\sigma_{t}$ equals the standard deviation of the conditional variance, $\sigma_{t}^{2}$, and $\lambda$ measures the volatility effect in the mean.

Alternative theoretical models give mixed results -- negative, positive, or independent relationships between output growth volatility and output growth. For example, the misperceptions theory, proposed originally by Friedman (1968), Phelps (1968), and Lucas (1972), argues that output fluctuates around its natural rate, reflecting price misperceptions due to monetary shocks. The long-run growth rate of potential output, however, reflects technology and other real factors. The standard dichotomy in macroeconomics implies no relationship between output volatility and its growth rate (i.e., $\lambda=0)$. Martin and Rogers $(1997,2000)$ argue 
that learning-by-doing generates growth whereby production complements productivityimproving activities and stabilization policy can positively affect human capital accumulation and growth. One natural conclusion, therefore, implies a negative relationship between output growth volatility and growth (i.e., $\lambda<0$ ). In contrast, Black (1987) argues that high output volatility and high growth coexist. According to Blackburn (1999), a relative increase in the volatility of shocks increases the pace of knowledge accumulation and, hence, growth, implying a positive relation between output growth volatility and growth (i.e., $\lambda>0$ ).

More recently, Fountas et al. (2006) consider the possibility of a two-way relationship between output growth and its volatility. The authors first estimate a bivariate GARCH specification of output growth and inflation. And then they recover the means and conditional variances for output growth and inflation to run a second-stage four-variable vectorautoregressive model to conduct Granger-causality tests. Using G7 examples, they find that output growth volatility positively affects output growth in all the seven countries, except Japan, and output growth negatively affects output growth volatility in Japan, Germany, and the U.S. and a zero effect in the rest of the countries. That is, a bi-directional causality between output growth and its volatility exists in Germany and the U.S., and one-way causality in Japan and the other four countries.

In a GARCH-M model, if output growth partly determines its volatility but is excluded in the variance equation, then the conditional variance equation is misspecified and GARCH-M estimates are not consistent (see Pagan and Ullah, 1988). Fountas and Karanasos (2006) and Fang and Miller (2008) develop a structural specification that incorporates the contemporaneous conditional volatility into the mean equation for output growth and lagged output growth into the conditional variance equation in their GARCH-M models. They both find a negative level effect 
in the variance for the U.S. and Fountas and Karanasos (2006) find no level effect in Japan. To avoid the GARCH-M model suffering from an endogeneity bias, we augment the variance equations (4) and (5) to include lagged output growth, respectively, as follows:

$$
\begin{aligned}
& \sigma_{t}^{2}=\alpha_{0}+\alpha_{1} \varepsilon_{t-1}^{2}+\beta_{1} \sigma_{t-1}^{2}+\theta y_{t-1}+\gamma D, \\
& \log \sigma_{t}^{2}=\alpha_{0}+\alpha_{1} \frac{\left|\varepsilon_{t-1}\right|}{\sigma_{t-1}}+\alpha_{2} \frac{\varepsilon_{t-1}}{\sigma_{t-1}}+\beta_{1} \log \sigma_{t-1}^{2}+\theta y_{t-1}+\gamma D,
\end{aligned}
$$

where $\theta$ measures the level effect of the output growth in variance. To the best of our knowledge, no economic theory models explicitly the effect of output growth on its volatility. The sign of $\theta$ is unknown. Fountas et al. (2006) argue that either a negative or a positive relation may occur. That is, an increase in output growth leads to more inflation, if both the Friedman (1977) hypothesis and the Taylor (1979) effect hold, then higher inflation raises inflation volatility and higher inflation volatility trades off with output volatility. Thus, output growth and its volatility are negatively related (i.e., $\theta<0$ ). Ungar and Zilberfarb (1993), however, show that higher inflation reduces inflation volatility, and thus a positive relation (i.e., $\theta>0$ ) may also occur.

Table 10 reports the GARCH and EGARCH in mean estimation results, where we include the mean-shift dummies, and the lagged output growth as well as the one-time structural break in the variance process. As noted earlier in Table 7, we already demonstrated that the $\mathrm{ARCH}(1)$ adequately captures the volatility of real GDP growth of Japan. Since most previous studies use GARCH(1,1)-M to model the relationship between output growth and its volatility, for comparison reason, we report both GARCH(1,1)-M and ARCH(1)-M estimation results. For the three models estimated, the coefficient of the conditional standard deviation $(\lambda)$ is negative but insignificant. The estimate $(\theta)$ of the lagged growth rate of output on its conditional variance is positive in the GARCH and ARCH models, but negative in the EGARCH specification, all 
with no significance. Other estimates and diagnostic statistics behave well. That is, the three dummies $\left(d_{1}, d_{2}\right.$, and $\left.\gamma\right)$ are significantly negative, the LR statistic suggests no IGARCH effect, and the residuals are normally distributed with no autocorrelations and heteroskedasticity, all at the 5-percent level. Based on the likelihood ratio test, $\mathrm{ARCH}(1)-\mathrm{M}$ performs as good as $\operatorname{GARCH}(1,1)-\mathrm{M}$, and the insignificant asymmetric measure $\alpha_{2}$ and persistence estimate $\beta_{1}$ imply that an $\mathrm{ARCH}(1)$ actually can replace the $\mathrm{EGARCH}$ model. The evidence further concludes no ARCH effect in the real growth rates of Japan after accounting for the change of the variance.

The insignificant estimate of $\lambda$ in the mean equation implies no relationship between output volatility and its growth. This result conforms to the misperception hypothesis and the previous empirical findings, using GARCH-M models, of Speight (1999) for the U.K., Fountas et al. (2004) for Japan, and Grier and Perry (2000), Fountas and Karanasos (2006), and Fang and Miller (2008) for the U.S. This finding, however, proves inconsistent with the discovery of a positive relationship by Caporale and McKiernan $(1996,1998)$ for the U.K. and the U.S., and by Fountas and Karanasos (2006) for Germany and Japan, as well as the discovery of a negative relationship by Macri and Sinha (2000) for Australia and by Henry and Olekaln (2002) for the U.S.

What factors may explain the differences in findings across studies? Caporale and McKiernan (1998) and Fountas and Karanasos (2006) use annual real GNP or IP (industrial production) data. Macri and Sinha (2000) use quarterly real GDP and IP data, although the real GDP data do not exhibit an ARCH effect. Caporale and McKiernan (1996), Speight (1999), and Grier and Perry (2000) use monthly IP to examine the effect of output growth volatility on its growth. The data frequency may provide another avenue for differences in findings. Existing 
research efforts, however, do not limit the phenomenon of the Great Moderation to quarterly output only. For example, Sensier and van Dijk (2004) find approximately 80 percent of 214 monthly U.S. macroeconomic time series, including IP, experience a break in the unconditional volatility over the period 1959-1999, with most breaks occurring after 1980. The finding of GARCH-M effects, significant or not, may prove spurious, since these researches fail to account for the structural change in the variance.

Regarding how the lagged growth rate of output affects its conditional variance, we use quarterly data and find no significant effect. Fountas and Karanasos (2006) employ annual data and report no level effect. Fountas et al. (2006) apply monthly data and identify a significant negative effect for Japan. We differ in reporting no positive effect in GARCH and no negative effect in EGARCH. Our GARCH-M estimation result proves robust to the outliers and the Great Moderation in the mean as well as in the variance.

\section{Conclusion}

This paper investigates volatility in quarterly real GDP growth rates for Japan during the period 1955:2 to 2008:2 as well as the relationship, if any, between output growth volatility and output growth. We begin by considering the possible effects, if any, of structural change on the volatility process. Our initial results, based on a GARCH and an EGARCH model, find strong evidence of volatility persistence and excess kurtosis in the growth rates. Subsequent analysis reveals that this conclusion does not prove robust to an additive outlier in the GARCH specifications and the Great Moderation in the mean and the variance of output growth at the break dates identified by the Bai and Perron $(1998,2003)$ algorithm. First, excess kurtosis drops substantially in the GARCH or vanishes in the EGARCH model that corrects for the additive outlier in the growth rates. Non-normal distribution partly reflects extraordinary changes in the 
data (Tables 2 and 4). Second, using the outlier-corrected growth series, the IGARCH effect or high volatility persistence remains in the specification that includes the mean-shift dummy variables in either a symmetric or an asymmetric model (Table 6). Third, the finding of a high volatility persistence measured by the GARCH or the EGARCH model disappears in the specification that includes a dummy variable for the structural break. The IGARCH effect proves spurious (Table 7). This result demonstrates a misspecification of the GARCH models, if researchers neglect the Great Moderation in the variance. Fourth, in a parsimonious ARCH-M model, our measure of volatility that corrects for the additive outlier and structural shifts in the mean and the volatility process finds that neither the volatility of output growth affects output growth, nor output growth affects its volatility (Table 10).

Using Japan as an example, our series of empirical evidence on volatility of real GDP growth indicate that GARCH estimates are sensitive to data and, thus, inferences prove biased without a more thorough examination of the data. Non-normally distributed growth rates may reflect changes in the data. Outlier-corrected data and dummy variables accounting for such changes produce lower volatility persistence and normally distributed residuals in GARCH estimation, either a symmetric or an asymmetric model. As a consequence, researchers need to examine outliers and each of the first four moments of residuals to guarantee adequateness of the GARCH model employed. One issue remains unresolved and deserves further attention: Why do Japan and the U.S. experience ten-year gap between their break dates for the Great Moderation, even though both experience the high degree of moderation in output volatility. 


\section{References}

Ahmed, S., Levin, A. and Wilson, B.A. (2004) Recent U.S. macroeconomic stability: Good policies, good practices, or good luck? Review of Economics and Statistics 86, 824-832.

Bai, J. and Perron, P. (1998) Estimating and testing linear models with multiple structural changes, Econometrica 66, 47-78.

Bai, J. and Perron, P. (2003) Computation and analysis of multiple structural change models, Journal of Applied Econometrics 18, 1-22.

Bali, R. and Guirguis, H. (2007) Extreme observations and non-normality in ARCH and GARCH, International Review of Economics \& Finance 16, 332-346.

Balke, N. and Fomby, T. B. (1994) Large shocks, small shocks, and economic fluctuations: Outliers in macroeconomic time series, Journal of Applied Econometrics 9, 181-200.

Bernanke, B.S. (2004) The Great Moderation, speech at Eastern Economic Association, Washington, February 20.

Berndt, E. K., Hall, B. H., Hall, R. E. and Hausmann, J. A. (1974) Estimation and inference in nonlinear structural models, Annals of Economic and Social Measurement 4, 653-665.

Bhar, R. and Hamori, S. (2003) Alternative characterization of the volatility in the growth rate of real GDP, Japan and the World Economy 15, 223-231.

Black, F. (1987) Business Cycles and Equilibrium, Basil Blackwell, New York.

Blackburn, K. (1999) Can stabilization policy reduce long-run growth? Economic Journal 109, $67-77$.

Blanchard, O. and Simon, J. (2001) The long and large decline in U.S. output volatility, Brookings Papers on Economic Activity 32, 135-174. 
Bollerslev, T. (1986) Generalized autoregressive conditional heteroskedasticity, Journal of Econometrics 31, 307-327.

Bollerslev, T. and Wooldridge, J. M. (1992) Quasi-maximum likelihood estimation and inference in dynamic models with time varying covariance, Econometric Reviews 11, 143-172.

Caporale, T. and McKiernan, B. (1996) The relationship between output variability and growth: Evidence from post war U.K. data, Scottish Journal of Political Economy 43, 229-236.

Caporale, T. and McKiernan, B. (1998) The Fischer Black hypothesis: Some time-series evidence, Southern Economic Journal 63, 765-771.

Charles, A. and Darné, O. (2005) Outliers and GARCH models in financial data, Economics Letters 86, 347-352.

Charles, A. and Darné, O. (2006) Large shocks and the September $11^{\text {th }}$ terrorist attacks on international stock markets, Economic Modelling 23, 683-698.

Chen, C. and Liu, L. (1993) Joint estimation of model parameters and outlier effects in time series, Journal of the American Statistical Association, 88, 284-297.

Cecchetti, S. G., Flores-Lagunes, A. and Krause, S. (2005) Assessing the sources of changes in the volatility of real growth, in The Changing Nature of the Business Cycle, ed. Christopher Kent and David Norman, Reserve Bank of Australia, 115-138.

Diebold, F. X. (1986) Comments on modelling the persistence of conditional variance, Econometric Reviews 5, 51-56.

Diebold, F. X. and Senhadji, A. S. (1996) The uncertain unit root in Real GNP: Comment, American Economic Review 86, 1291-1298.

Eggers, A. and Ioannides, Y. M. (2006) The role of output composition in the stabilization of U.S. output growth, Journal of Macroeconomics 28, 585-595. 
Engle, R. F. and Bollerslev, T. (1986) Modelling the persistence of conditional variance, Econometric Reviews 5, 1-50.

Engle, R. F., Lilien, D. and Robins, R. (1987) Estimating time varying risk premia in the term structure: The ARCH-M model, Econometrica 55, 391-407.

Fang, W. and Miller, S. M. (2008) The Great Moderation and the relationship between output growth and its volatility, Southern Economic Journal 74, 819-838.

Fountas, S. and Karanasos, M. (2006) The relationship between economic growth and real uncertainty in the G3, Economic Modelling 23, 638-647.

Fountas, S., Karanasos, M., and Kim, J. (2006) Inflation uncertainty, output growth uncertainty and macroeconomic performance, Oxford Bulletin of Economics and Statistics 68, 319343.

Fountas, S., Karanasos, M., and Mendoza, A. (2004) Output variability and economic growth: the Japanese case, Bulletin of Economic Research 56, 353-363.

Franses, P. H. and Ghijsels, H. (1999) Additive outliers, GARCH and forecasting volatility, International Journal of Forecasting 15, 1-9.

Franses, P. H. and van Dijk, D. H. (2004) Non-linear time series models in empirical finance, Cambridge University Press, Cambridge.

Friedman, M. (1968) The role of monetary policy, American Economic Review 58, 1-17.

Friedman, M. (1977) Nobel lecture: inflation and unemployment, Journal of Political Economy $85,451-472$.

Grier, K. B. and Perry, M. J. (2000) The effects of real and nominal uncertainty on inflation and output growth: Some GARCH-M evidence, Journal of Applied Econometrics 15, 45-58. 
Hamilton, J. D. and Susmel, R. (1994) Autoregressive conditional heteroskedasticity and changes in regime, Journal of Econometrics 64, 307-333.

Hamori, S. (2000) Volatility of real GDP: Some evidence from the United States, the United Kingdom and Japan, Japan and the World Economy 12, 143-152.

Henry, O. T. and Olekalns, N. (2002) The effect of recessions on the relationship between output variability and growth, Southern Economic Journal 68, 683-692.

Herrera, A. M. and Pesavento, E. (2005) The decline in U.S. output volatility: structural changes and inventory investment, Journal of Business and Economic Statistics 23, 462-472.

Hillebrand, E. (2005) Neglecting parameter changes in GARCH models, Journal of Econometrics 129, 121-138.

Ho, K. Y. and Tsui, A. K. C. (2003) Asymmetric volatility of real GDP: Some evidence from Canada, Japan, the United Kingdom and the United States, Japan and the World Economy 15, 437-445.

Inclán, C. and Tiao, G. C. (1994) Use of cumulative sums of squares for retrospective detection of changes of variance, Journal of the American Statistical Association, 89, 913-923.

Kim, C. J. and Nelson, C. R. (1999) Has the U.S. economy become more stable? A Bayesian approach based on a Markov-Switching model of the business cycle, Review of Economics and Statistics 81, 1-10.

Kim, C. J., Nelson, C. R. and Startz, R. (1998) Testing for mean reversion in heteroskedastic data based on Gibbs sampling augmented randomization, Journal of Empirical Finance $5,131-154$.

Krämer, W. and Azamo, B. T. (2007) Structural change and estimated persistence in the GARCH(1,1)-model, Economics Letters 97, 17-23. 
Lamoureux, C. G. and Lastrapes, W. D. (1990) Persistence in variance, structural change and the GARCH model, Journal of Business and Economic Statistics 8, 225-234.

Lastrapes, W. D. (1989) Exchange rate volatility and U.S. monetary policy: An ARCH application, Journal of Money, Credit, and Banking 21, 66-77.

Lucas, R. E. (1972) Expectations and the neutrality of money, Journal of Economic Theory 4, 103-124.

Macri, J., and Sinha, D. (2000) Output variability and economic growth: The case of Australia, Journal of Economics and Finance 24, 275-282.

Martin, P. and Rogers, C.A. (1997) Stabilization policy, learning by doing, and economic growth, Oxford Economic Papers 49, 152-166.

Martin, P. and Rogers, C.A. (2000) Long-term growth and short-term economic instability, European Economic Review 44, 359-381.

McConnell, M. M. and Perez-Quiros, G. (2000) Output fluctuations in the United States: What has changed since the early 1980's? American Economic Review 90, 1464-1476.

Mikosch, T. and Stărică, C. (2004) Non-stationarities in financial time series, the long-range dependence, and the IGARCH effects, Review of Economics and Statistics 86, 378-390.

Mills, T. C. and Wang, P. (2003) Have output growth rates stabilized? Evidence from the G-7 economies, Scottish Journal of Political Economy 50, 232-246.

Nelson, D. B. (1991) Conditional heteroskedasticity in asset returns: A new approach, Econometrica 59, 347-370.

Pagan, A. and Ullah, A. (1988) The econometric analysis of models with risk terms, Journal of Applied Econometrics 3, 87-105. 
Peña, D. (2001) Outliers, influential observations, and missing data, in A Course in Time Series Analysis, ed. Daniel Peña, George C. Tiao, and Ruey S. Tsay, John Wiley \& Son, Inc., 136-170.

Phelps, E. S. (1968) Money wage dynamics and labor market equilibrium, Journal of Political Economy 76, 678-711.

Rapach, D. E. and Strauss, J. K. (2008) Structural breaks and GARCH models of exchange rate volatility, Journal of Applied Econometrics 23, 65-90.

Sansó, A., Arragó, V. and Carrion, J. L. (2004) Testing for change in the unconditional variance of financial time series, Revista de Economiá Financiera 4, 32-53.

Sensier, M. and van Dijk, D. (2004) Testing for volatility changes in U.S. macroeconomic time series, Review of Economics and Statistics 86, 833-839.

Speight, A. E. H. (1999) U.K. output variability and growth: Some further evidence, Scottish Journal of Political Economy 46, 175-184.

Stock, J. H. and Watson, M. W. (2003) Has the business cycle changed? Evidence and explanations, Monetary Policy and Uncertainty: Adapting to a Changing Economy, proceedings of symposium sponsored by Federal Reserve Bank of Kansas City, Jackson Hole, Wyo., 9-56.

Stock, J. H. and Watson, M. W. (2005) Understanding changes in international business cycle dynamics, Journal of the European Economic Association 3, 968-1006.

Summers, P. M. (2005) What caused the Great Moderation? Some cross-country evidence, Economic Review (Third Quarter), Federal Reserve Bank of Kansas City, 5-32.

Taylor, J. (1979) Estimation and control of a macroeconomic model with rational expectations, Econometrica 47, 1267-1286. 
Tolvi, J. (2001) Outliers in eleven Finnish macroeconomic time series, Finnish Economic Papers $14,14-32$.

Tsay, R. S. (1988) Outliers, level shifts and variance changes in time series, Journal of Forecasting 7, 1-20.

Tzavalis, E. and Wickens, M. R. (1995) The persistence in volatility of the U.S. term premium 1970-1986, Economics Letters 49, 381-389.

Ungar, M. and Zilberfarb, B. (1993) Inflation and its unpredictability - theory and empirical evidence, Journal of Money, Credit, and Banking 25, 709-720.

van Dijk, D., Franses, P. H., and Lucas, A. (1999) Testing for ARCH in the presence of additive outliers, Journal of Applied Econometrics 14, 539-562.

Verhoeven, P. and McAleer, M. (2004) Fat tails and asymmetry in financial volatility models, Mathematics and Computers in Simulation 64, 351-361. 
Table 1: Descriptive Statistics for Real GDP Growth, 1955-2008

\begin{tabular}{|c|c|c|c|c|c|}
\hline Mean & 1.1667 & $L B Q(1)$ & $\begin{array}{l}19.7873^{*} \\
{[0.0000]}\end{array}$ & $L B Q^{2}(1)$ & $\begin{array}{l}5.0188^{*} \\
{[0.0250]}\end{array}$ \\
\hline Standard deviation & 1.3037 & $L B Q(2)$ & $\begin{array}{l}65.8448^{*} \\
{[0.0000]}\end{array}$ & $L B Q^{2}(2)$ & $\begin{array}{c}46.9315^{*} \\
{[0.0000]}\end{array}$ \\
\hline Maximum & 6.8306 & $L B Q(3)$ & $\begin{array}{c}104.6101^{*} \\
{[0.0000]}\end{array}$ & $L B Q^{2}(3)$ & $\begin{array}{l}63.1776^{*} \\
{[0.0000]}\end{array}$ \\
\hline Minimum & -3.4964 & $L B Q(4)$ & $\begin{array}{c}130.0250^{*} \\
{[0.0000]}\end{array}$ & $L B Q^{2}(4)$ & $\begin{array}{l}81.4277^{*} \\
{[0.0000]}\end{array}$ \\
\hline Skewness & $\begin{array}{c}0.6906^{*} \\
{[0.0000]}\end{array}$ & $L B Q(5)$ & $\begin{array}{c}154.5388^{*} \\
{[0.0000]}\end{array}$ & $L B Q^{2}(5)$ & $\begin{array}{l}98.0268^{*} \\
{[0.0000]}\end{array}$ \\
\hline Kurtosis & $\begin{array}{l}2.2556^{*} \\
{[0.0000]}\end{array}$ & $L B Q(6)$ & $\begin{array}{c}174.5210 * \\
{[0.0000]}\end{array}$ & $L B Q^{2}(6)$ & $\begin{array}{c}102.2001^{*} \\
{[0.0000]}\end{array}$ \\
\hline Normality test & $\begin{array}{l}61.7964^{*} \\
{[0.0000]}\end{array}$ & $L B Q(7)$ & $\begin{array}{c}205.6469^{*} \\
{[0.0000]}\end{array}$ & $L B Q^{2}(7)$ & $\begin{array}{c}126.6172 * \\
{[0.0000]}\end{array}$ \\
\hline
\end{tabular}

Note: $\quad$ P-values appear in brackets; 0.0000 indicates less than 0.00005 . The measures of skewness and kurtosis are normally distributed as $N(0,6 / T)$ and $N(0,24 / T)$, respectively, where $T(=212)$ equals the number of observations. $L B Q(k)$ and $L B Q^{2}(k)$ equal Ljung-Box Q-statistics distributed asymptotically as $\chi^{2}$ with $k$ degrees of freedom, testing for level and squared terms for autocorrelations up to $k$ lags.

* denotes 5-percent significance level. 
Table 2: $\quad$ Model Estimation

Panel A. GARCH(1,1) Estimates

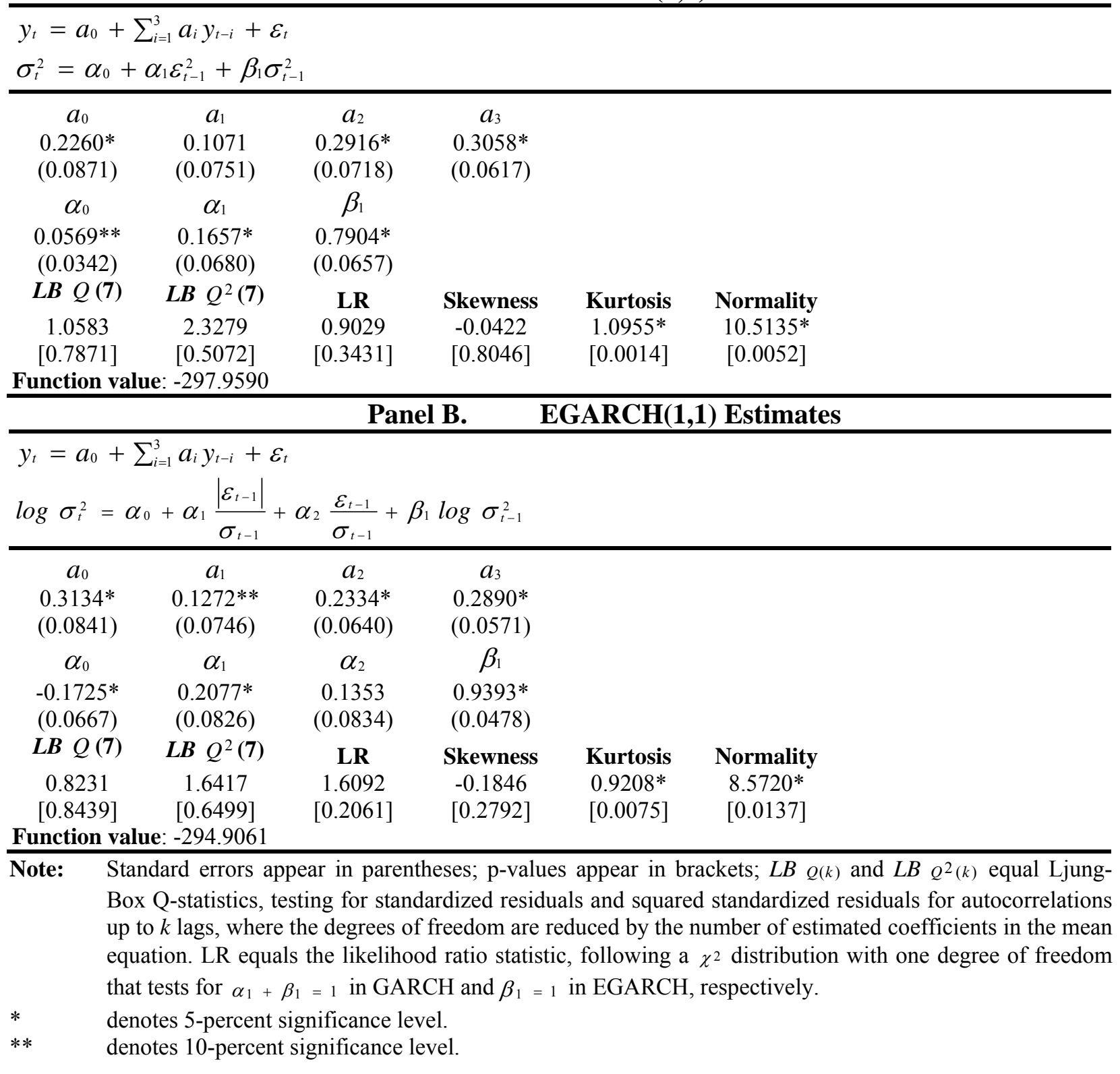


Table 3: Descriptive Statistics for Outlier-Corrected Real GDP Growth, 1955-2008

\begin{tabular}{|c|c|c|c|c|c|}
\hline Mean & 1.2163 & $L B Q(1)$ & $\begin{array}{c}20.9852^{*} \\
{[0.0000]}\end{array}$ & $L B Q^{2}(1)$ & $\begin{array}{l}5.1019^{*} \\
{[0.0238]}\end{array}$ \\
\hline Standard deviation & 1.2659 & $L B Q(2)$ & $\begin{array}{l}69.9809^{*} \\
{[0.0000]}\end{array}$ & $L B Q^{2}(2)$ & $\begin{array}{c}47.8615^{*} \\
{[0.0000]}\end{array}$ \\
\hline Maximum & 6.8306 & $L B Q(3)$ & $\begin{array}{c}109.3186^{*} \\
{[0.0000]}\end{array}$ & $L B Q^{2}(3)$ & $\begin{array}{l}65.1718^{*} \\
{[0.0000]}\end{array}$ \\
\hline Minimum & -1.9698 & $L B Q(4)$ & $\begin{array}{c}138.8182 * \\
{[0.0000]}\end{array}$ & $L B Q^{2}(4)$ & $\begin{array}{l}81.5515^{*} \\
{[0.0000]}\end{array}$ \\
\hline Skewness & $\begin{array}{c}0.8995^{*} \\
{[0.0000]}\end{array}$ & $L B Q(5)$ & $\begin{array}{c}168.8427^{*} \\
{[0.0000]}\end{array}$ & $L B Q^{2}(5)$ & $\begin{array}{c}96.3839^{*} \\
{[0.0000]}\end{array}$ \\
\hline Kurtosis & $\begin{array}{l}1.8754^{*} \\
{[0.0000]}\end{array}$ & $L B Q(6)$ & $\begin{array}{c}192.5618^{*} \\
{[0.0000]}\end{array}$ & $L B Q^{2}(6)$ & $\begin{array}{c}100.4749^{*} \\
{[0.0000]}\end{array}$ \\
\hline Normality test & $\begin{array}{c}59.6601 * \\
{[0.0000]}\end{array}$ & $L B Q(7)$ & $\begin{array}{c}229.6830^{*} \\
{[0.0000]}\end{array}$ & $L B Q^{2}(7)$ & $\begin{array}{c}125.2782^{*} \\
{[0.0000]}\end{array}$ \\
\hline
\end{tabular}

Note: $\quad$ See Table 1.

* denotes 5-percent significance level. 
Table 4: $\quad$ Model Estimation, Outlier-Corrected Growth Series

Panel A. GARCH(1,1) Estimates, Outlier-Corrected

\begin{tabular}{|c|c|c|c|c|c|}
\hline \multicolumn{6}{|c|}{$\begin{array}{l}y_{t}=a_{0}+\sum_{i=1}^{3} a_{i} y_{t-i}+\varepsilon_{t} \\
\sigma_{t}^{2}=\alpha_{0}+\alpha_{1} \varepsilon_{t-1}^{2}+\beta_{1} \sigma_{t-1}^{2}\end{array}$} \\
\hline$a_{0}$ & $a_{1}$ & $a_{2}$ & $a_{3}$ & & \\
\hline $\begin{array}{l}0.2480 * \\
(0.0861)\end{array}$ & $\begin{array}{c}0.1283 * * \\
(0.0745)\end{array}$ & $\begin{array}{c}0.2713 * \\
(0.0674)\end{array}$ & $\begin{array}{l}0.3008 * \\
(0.0625)\end{array}$ & & \\
\hline$\alpha_{0}$ & $\alpha_{1}$ & $\beta_{1}$ & & & \\
\hline $\begin{array}{c}0.0485 \\
(0.0340)\end{array}$ & $\begin{array}{l}0.1351^{*} \\
(0.0684)\end{array}$ & $\begin{array}{l}0.8174 * \\
(0.0793)\end{array}$ & & & \\
\hline$L B Q(7)$ & $L B Q^{2}(7)$ & LR & Skewness & Kurtosis & Normality \\
\hline $\begin{array}{c}1.6654 \\
{[0.6446]}\end{array}$ & $\begin{array}{c}2.5268 \\
{[0.4704]}\end{array}$ & $\begin{array}{c}1.4004 \\
{[0.2380]}\end{array}$ & $\begin{array}{c}0.1786 \\
{[0.2952]}\end{array}$ & $\begin{array}{c}0.5810^{* *} \\
{[0.0917]}\end{array}$ & $\begin{array}{c}4.0519 \\
{[0.1318]}\end{array}$ \\
\hline Function va & -290.0513 & & & & \\
\hline \multicolumn{3}{|c|}{ Panel B. } & \multicolumn{3}{|c|}{ EGARCH(1,1) Estimates, Outlier-Corrected } \\
\hline \multicolumn{6}{|c|}{$\begin{array}{l}y_{t}=a_{0}+\sum_{i=1}^{3} a_{i} y_{t-i}+\varepsilon_{t} \\
\log \sigma_{t}^{2}=\alpha_{0}+\alpha_{1} \frac{\left|\varepsilon_{t-1}\right|}{\sigma_{t-1}}+\alpha_{2} \frac{\varepsilon_{t-1}}{\sigma_{t-1}}+\beta_{1} \log \sigma_{t-1}^{2}\end{array}$} \\
\hline $\begin{array}{l}a_{0} \\
0.2881 * \\
(0.0870)\end{array}$ & $\begin{array}{c}a_{1} \\
0.1714^{*} \\
(0.0677)\end{array}$ & $\begin{array}{c}a_{2} \\
0.2500 * \\
(0.0720)\end{array}$ & $\begin{array}{c}a_{3} \\
0.2972 * \\
(0.0744)\end{array}$ & & \\
\hline$\alpha_{0}$ & $\alpha_{1}$ & $\alpha_{2}$ & $\beta_{1}$ & & \\
\hline $\begin{array}{l}-0.1780 * \\
(0.0741)\end{array}$ & $\begin{array}{l}0.2027 * \\
(0.0906)\end{array}$ & $\begin{array}{l}0.1721 * \\
(0.0676)\end{array}$ & $\begin{array}{l}0.9137 * \\
(0.0539)\end{array}$ & & \\
\hline$L B Q(7)$ & $L B Q^{2}(7)$ & LR & Skewness & Kurtosis & Normality \\
\hline $\begin{array}{c}1.4308 \\
{[0.6983]} \\
\text { Function va }\end{array}$ & $\begin{array}{l}1.5209 \\
{[0.6774]} \\
-286.8589\end{array}$ & $\begin{array}{c}2.5577 \\
{[0.1113]}\end{array}$ & $\begin{array}{c}0.1110 \\
{[0.5152]}\end{array}$ & $\begin{array}{c}0.2099 \\
{[0.5424]}\end{array}$ & $\begin{array}{c}0.8133 \\
{[0.6658]}\end{array}$ \\
\hline
\end{tabular}

Note: See Table 2.

* denotes 5-percent significance level.

** denotes 10-percent significance level. 
Table 5: Break Date and Structural Stability Test

Panel A. Structural Break Test in Mean

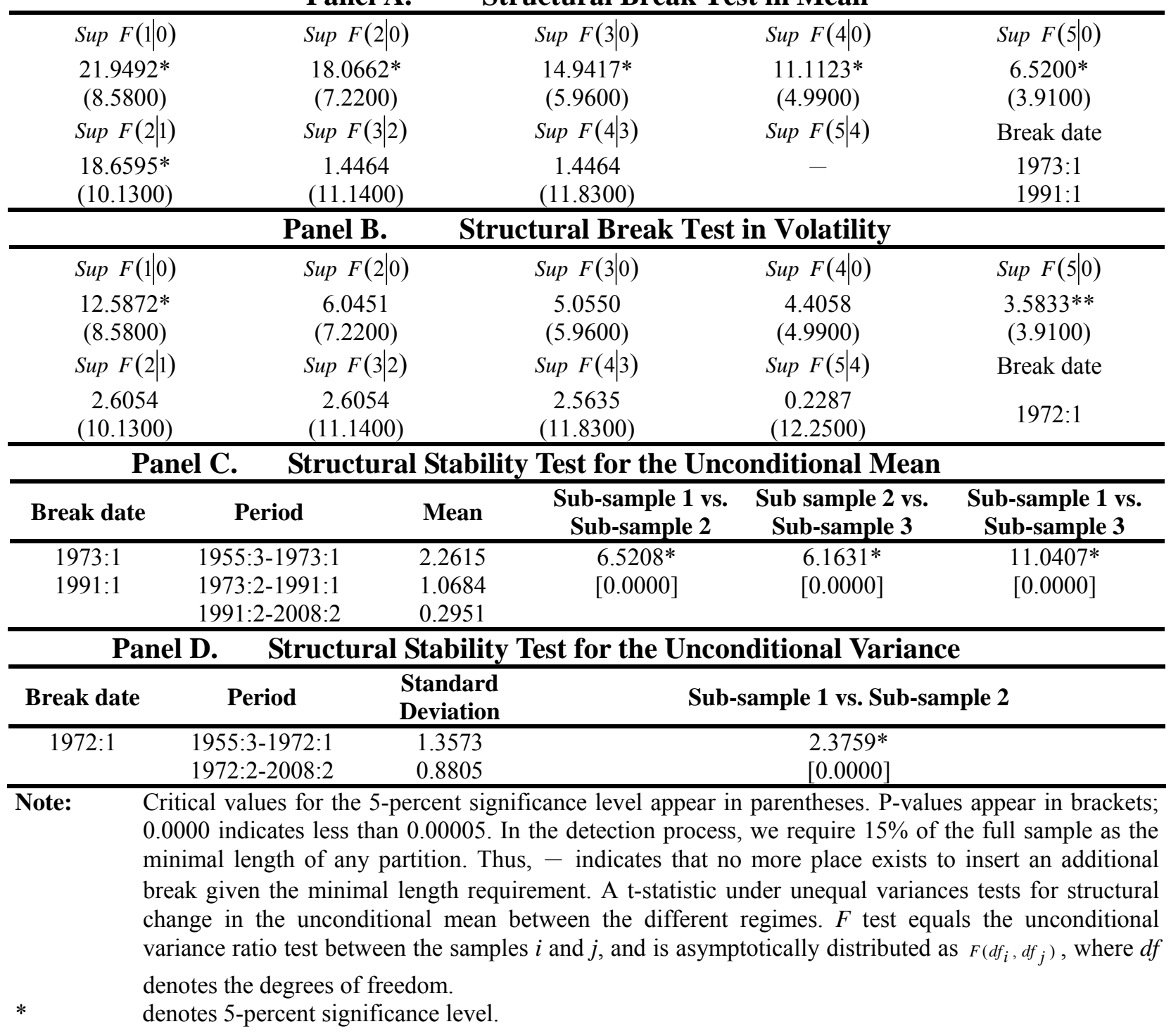


Table 6: $\quad$ Model Estimation with Dummies in Mean

Panel A. GARCH(1,1) Estimates

$y_{t}=a_{0}+\sum_{i-1}^{3} a_{i} y_{t-i}+d_{1} D_{1}+d_{2} D_{2}+\varepsilon_{t}$

$\sigma_{t}^{2}=\alpha_{0}+\alpha_{1} \varepsilon_{t-1}^{2}+\beta_{1} \sigma_{t-1}^{2}$

where $D_{1}=1$ for $\mathrm{t}>1973: 1$ and $D_{2}=1$ for $\mathrm{t}>1991: 1 ; 0$ otherwise.

\begin{tabular}{cccccc}
\hline$a_{0}$ & $a_{1}$ & $a_{2}$ & $a_{3}$ & $d_{1}$ & $d_{2}$ \\
$1.9195^{*}$ & -0.0702 & 0.0940 & $0.1276^{*}$ & $-1.0522^{*}$ & $-0.6083^{*}$ \\
$(0.2806)$ & $(0.0805)$ & $(0.0754)$ & $(0.0625)$ & $(0.2229)$ & $(0.1383)$ \\
$\alpha_{0}$ & $\alpha_{1}$ & $\beta_{1}$ & & & \\
0.0239 & 0.0692 & $0.8968^{*}$ & & & \\
$(0.0305)$ & $(0.0601)$ & $(0.0890)$ & & & \\
$\mathbf{L B} Q \mathbf{( 7 )}$ & $\mathbf{L B} Q^{2} \mathbf{( 7 )}$ & $\mathbf{L R}$ & Skewness & Kurtosis & Normality \\
0.7309 & 4.5497 & 0.7006 & 0.2109 & $0.8638^{*}$ & $8.0471^{*}$ \\
{$[0.8659]$} & {$[0.2078]$} & {$[0.4036]$} & {$[0.2165]$} & {$[0.0121]$} & {$[0.0178]$} \\
Function value: -273.4982 & \multicolumn{7}{c}{ Panel B. } & EGARCH(1,1) Estimates \\
\hline \multicolumn{7}{c}{} \\
\hline
\end{tabular}

$y_{t}=a_{0}+\sum_{i-1}^{3} a_{i} y_{t-i}+d_{1} D_{1}+d_{2} D_{2}+\varepsilon_{t}$

$\log \sigma_{t}^{2}=\alpha_{0}+\alpha_{1} \frac{\left|\varepsilon_{t-1}\right|}{\sigma_{t-1}}+\alpha_{2} \frac{\varepsilon_{t-1}}{\sigma_{t-1}}+\beta_{1} \log \sigma_{t-1}^{2}$

where $D_{1}=1$ for $\mathrm{t}>1973: 1$ and $D_{2}=1$ for $\mathrm{t}>1991: 1 ; 0$ otherwise.

\begin{tabular}{cccccc}
\hline$a_{0}$ & $a_{1}$ & $a_{2}$ & $a_{3}$ & $d_{1}$ & $d_{2}$ \\
$1.6846^{*}$ & -0.0175 & 0.0902 & $0.1329^{*}$ & $-0.8508^{*}$ & $-0.5559^{*}$ \\
$(0.2478)$ & $(0.0805)$ & $(0.0712)$ & $(0.0583)$ & $(0.1970)$ & $(0.1308)$ \\
$\alpha_{0}$ & $\alpha_{1}$ & $\alpha_{2}$ & $\beta_{1}$ & & \\
$-0.1941^{* *}$ & 0.2184 & 0.0949 & $0.9272^{*}$ & & \\
$(0.1068)$ & $(0.1355)$ & $(0.0627)$ & $(0.0388)$ & & \\
$\mathbf{L B} Q(7)$ & $\mathbf{L B} Q^{2}(7)$ & $\mathbf{L R}$ & Skewness & Kurtosis & Normality \\
0.5269 & 3.0887 & $3.4956^{* *}$ & $0.2889^{* *}$ & $0.6884^{*}$ & $7.0361^{*}$ \\
{$[0.9129]$} & {$[0.3781]$} & {$[0.0630]$} & {$[0.0904]$} & {$[0.0457]$} & {$[0.0296]$} \\
Function value: -273.1138 & & & & \\
\hline
\end{tabular}

Note: See Table 2 . The coefficients $d_{1}$ and $d_{2}$ correspond to the two dummy variables in the mean equation.

* denotes 5-percent significance level.

** denotes 10-percent significance level. 
Table 7: $\quad$ Model Estimation with Structural Breaks in Mean and Variance Panel A. GARCH(1,1) Estimates

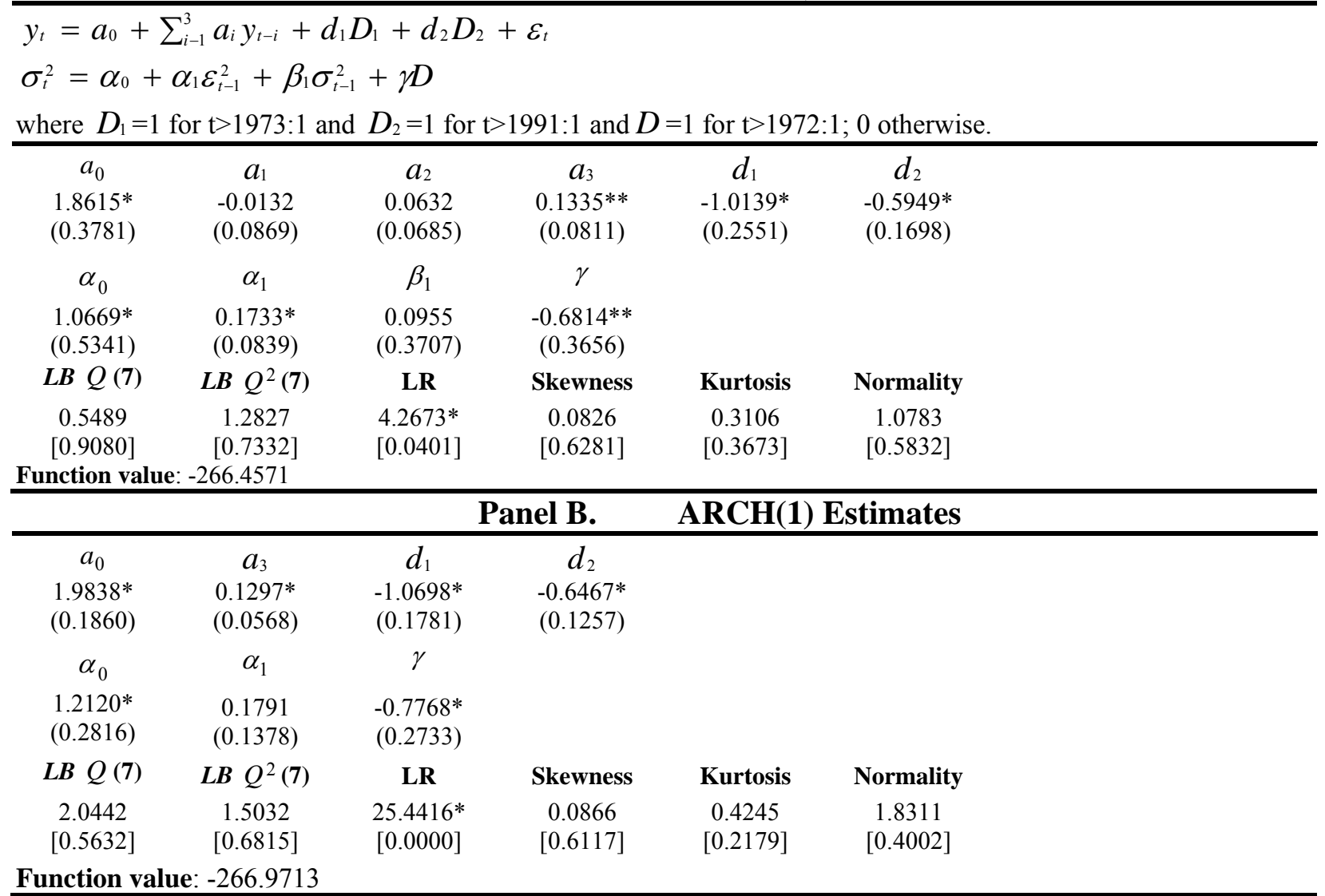

\section{Panel C. EGARCH(1,1) Estimates}

$y_{t}=a_{0}+\sum_{i-1}^{3} a_{i} y_{t-i}+d_{1} D_{1}+d_{2} D_{2}+\varepsilon_{t}$

$\log \sigma_{t}^{2}=\alpha_{0}+\alpha_{1} \frac{\left|\varepsilon_{t-1}\right|}{\sigma_{t-1}}+\alpha_{2} \frac{\varepsilon_{t-1}}{\sigma_{t-1}}+\beta_{1} \log \sigma_{t-1}^{2}+\gamma D$

where $D_{1}=1$ for $\mathrm{t}>1973: 1$ and $D_{2}=1$ for $\mathrm{t}>1991: 1$ and $D=1$ for $\mathrm{t}>1972: 1 ; 0$ otherwise.

\begin{tabular}{cccccc}
$a_{0}$ & $a_{1}$ & $a_{2}$ & $a_{3}$ & $d_{1}$ & $d_{2}$ \\
$1.5858^{*}$ & 0.0374 & 0.0853 & $0.1548^{*}$ & $-0.8253^{*}$ & $-0.5670^{*}$ \\
$(0.3249)$ & $(0.0775)$ & $(0.0638)$ & $(0.0691)$ & $(0.2325)$ & $(0.1639)$ \\
$\alpha_{0}$ & $\alpha_{1}$ & $\alpha_{2}$ & $\beta_{1}$ & $\gamma$ & \\
0.0617 & $0.2143^{* *}$ & $0.1795^{* *}$ & 0.2604 & $-0.7835^{* *}$ & \\
$(0.1690)$ & $(0.1276)$ & $(0.0953)$ & $(0.2450)$ & $(0.4124)$ & \\
$\mathbf{L B} Q \mathbf{( 7 )}$ & $\mathbf{L B} Q^{2} \mathbf{( 7 )}$ & $\mathbf{L R}$ & Skewness & Kurtosis & Normality \\
0.7189 & 1.9948 & $9.1104^{*}$ & 0.1590 & 0.4944 & 3.0101 \\
{$[0.8687]$} & {$[0.5734]$} & {$[0.0029]$} & {$[0.3512]$} & {$[0.1513]$} & {$[0.2220]$} \\
Function value: -268.3808 & & & & \\
\hline
\end{tabular}

Note: See Table 2 and Table 6 . The coefficient $\gamma$ corresponds to the dummy variable in the variance equation.

* denotes 5-percent significance level.

** denotes 10-percent significance level. 
Table 8: $\quad$ Model Estimation with Dummies in Mean

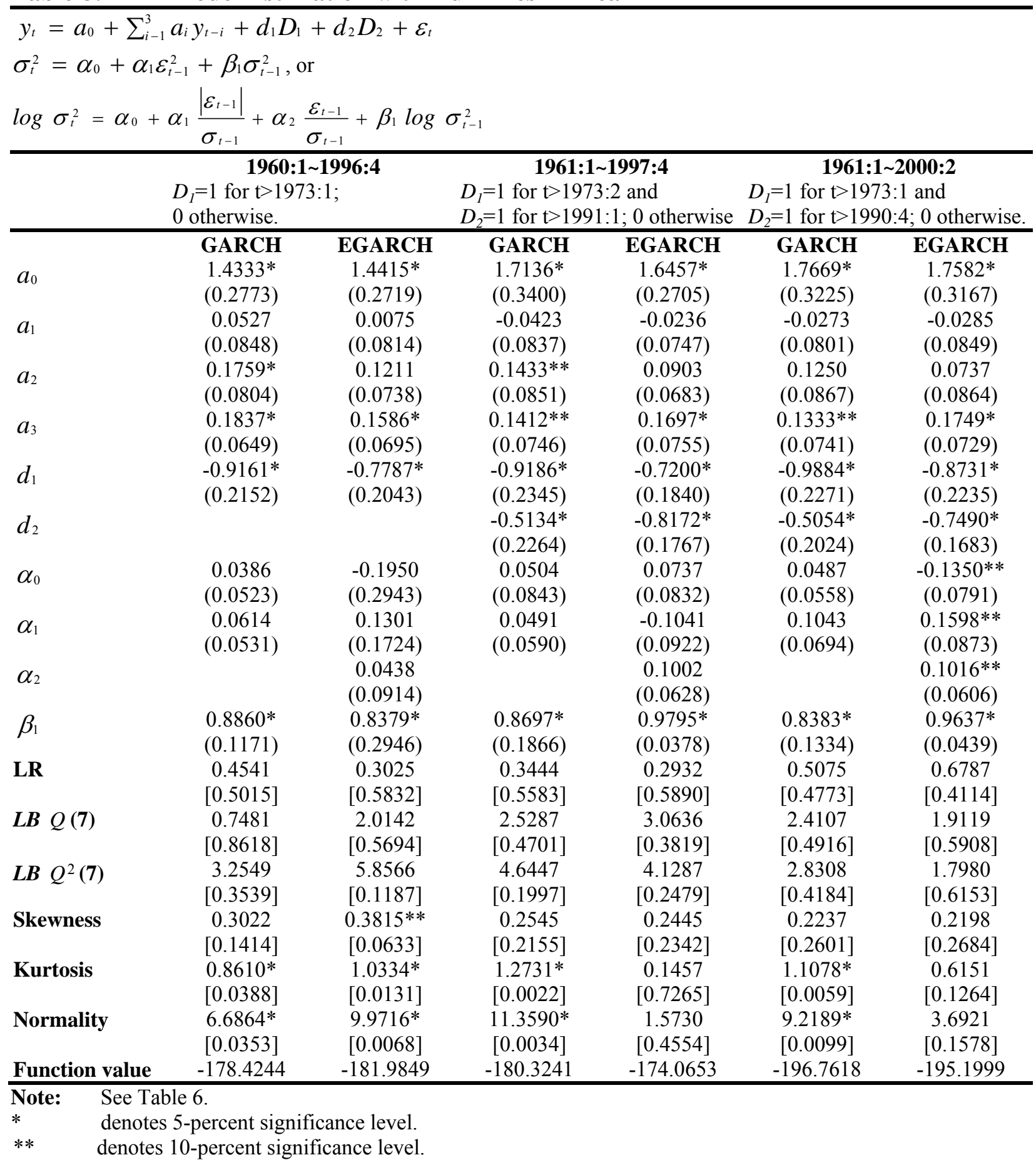


Table 9: $\quad$ Model Estimation with Structural Breaks in Mean and Variance

\begin{tabular}{|c|c|c|c|c|c|c|}
\hline \multicolumn{7}{|c|}{$\begin{array}{l}y_{t}=a_{0}+\sum_{i-1}^{3} a_{i} y_{t-i}+d_{1} D_{1}+d_{2} D_{2}+\varepsilon_{t} \\
\sigma_{t}^{2}=\alpha_{0}+\alpha_{1} \varepsilon_{t-1}^{2}+\beta_{1} \sigma_{t-1}^{2}+\gamma D, \text { or } \\
\log \sigma_{t}^{2}=\alpha_{0}+\alpha_{1} \frac{\left|\varepsilon_{t-1}\right|}{\sigma_{t-1}}+\alpha_{2} \frac{\varepsilon_{t-1}}{\sigma_{t-1}}+\beta_{1} \log \sigma_{t-1}^{2}+\gamma D\end{array}$} \\
\hline & $\begin{array}{l}\text { 1960: } \\
D_{1}=1 \text { for } t>19 \\
D=1 \text { for } t>19 \\
0 \text { otherwise. }\end{array}$ & $\begin{array}{l}996: 4 \\
\text { and } \\
\text {; }\end{array}$ & $\begin{array}{l}\quad \mathbf{1 9 6 1} \\
D_{1}=1 \text { for } \mathrm{t}>1 \mathrm{C} \\
D_{2}=1 \text { for } \mathrm{t}>1 \mathrm{C} \\
D=1 \text { for } \mathrm{t}>1 \mathrm{C} \\
0 \text { otherwise. }\end{array}$ & $\begin{array}{l}997: 4 \\
2, \\
1 \text { and } \\
3 ;\end{array}$ & $\begin{array}{l}\quad \mathbf{1 9 6 1} \\
D_{1}=1 \text { for } \mathrm{t}>1 \mathrm{c} \\
D_{2}=1 \text { for } \mathrm{t}>1 \mathrm{c} \\
D=1 \text { for } \mathrm{t}>1 \mathrm{C} \\
0 \text { otherwise. }\end{array}$ & $\begin{array}{l}\text { 000:2 } \\
1 \text { and } \\
\text {; }\end{array}$ \\
\hline & GARCH & EGARCH & GARCH & EGARCH & GARCH & EGARCH \\
\hline$a_{0}$ & $\begin{array}{c}1.6189^{*} \\
(0.3528)\end{array}$ & $\begin{array}{l}1.3823^{*} \\
(0.2711)\end{array}$ & $\begin{array}{l}1.7716^{*} \\
(0.3395)\end{array}$ & $\begin{array}{c}1.4271^{*} \\
(0.2989)\end{array}$ & $\begin{array}{c}1.9241 * \\
(0.3465)\end{array}$ & $\begin{array}{c}1.5140^{*} \\
(0.4174)\end{array}$ \\
\hline$a_{1}$ & $\begin{array}{c}0.0169 \\
(0.0971)\end{array}$ & $\begin{array}{c}0.0589 \\
(0.0803)\end{array}$ & $\begin{array}{l}-0.0616 \\
(0.0996)\end{array}$ & $\begin{array}{l}-0.0494 \\
(0.0837)\end{array}$ & $\begin{array}{l}-0.0289 \\
(0.0957)\end{array}$ & $\begin{array}{c}0.0450 \\
(0.0829)\end{array}$ \\
\hline$a_{2}$ & $\begin{array}{c}0.1390 \\
(0.0935)\end{array}$ & $\begin{array}{c}0.1097 \\
(0.0679)\end{array}$ & $\begin{array}{c}0.1171 * * \\
(0.0706)\end{array}$ & $\begin{array}{l}0.1597 * \\
(0.0604)\end{array}$ & $\begin{array}{c}0.0602 \\
(0.0773)\end{array}$ & $\begin{array}{c}0.0710 \\
(0.0906)\end{array}$ \\
\hline$a_{3}$ & $\begin{array}{c}0.0597 \\
(0.0900)\end{array}$ & $\begin{array}{l}0.2152 * \\
(0.0569)\end{array}$ & $\begin{array}{c}0.1668 * * \\
(0.0910)\end{array}$ & $\begin{array}{l}0.1983^{*} \\
(0.0749)\end{array}$ & $\begin{array}{c}0.1558 * * \\
(0.0891)\end{array}$ & $\begin{array}{l}0.1686^{*} \\
(0.0798)\end{array}$ \\
\hline$d_{1}$ & $\begin{array}{c}-0.7370^{*} \\
(0.2660)\end{array}$ & $\begin{array}{c}-0.8246^{*} \\
(0.2012)\end{array}$ & $\begin{array}{l}-0.9575^{*} \\
(0.2313)\end{array}$ & $\begin{array}{c}-0.7388^{*} \\
(0.2052)\end{array}$ & $\begin{array}{c}-1.1448^{*} \\
(0.2364)\end{array}$ & $\begin{array}{c}-0.8206^{*} \\
(0.2790)\end{array}$ \\
\hline$d_{2}$ & & & $\begin{array}{l}-0.6574 * \\
(0.2228)\end{array}$ & $\begin{array}{l}-0.4319^{*} \\
(0.1725)\end{array}$ & $\begin{array}{c}-0.6766^{*} \\
(0.1818)\end{array}$ & $\begin{array}{l}-0.4714^{*} \\
(0.2270)\end{array}$ \\
\hline$\alpha_{0}$ & $\begin{array}{l}0.4145^{*} \\
(0.0876)\end{array}$ & $\begin{array}{c}0.3297 \\
(0.4473)\end{array}$ & $\begin{array}{l}1.0575^{*} \\
(0.4040)\end{array}$ & $\begin{array}{c}0.2809 \\
(0.3419)\end{array}$ & $\begin{array}{l}0.9128^{*} \\
(0.4374)\end{array}$ & $\begin{array}{c}0.1801 \\
(0.3004)\end{array}$ \\
\hline$\alpha_{1}$ & $\begin{array}{c}0.0232 \\
(0.0844)\end{array}$ & $\begin{array}{c}0.0089 \\
(0.1639)\end{array}$ & $\begin{array}{c}0.1870 \\
(0.1436)\end{array}$ & $\begin{array}{c}0.1377 * * \\
(0.0831)\end{array}$ & $\begin{array}{l}0.3106^{*} \\
(0.1343)\end{array}$ & $\begin{array}{c}0.1695 \\
(0.1032)\end{array}$ \\
\hline$\alpha_{2}$ & & $\begin{array}{l}-0.1005 \\
(0.0613)\end{array}$ & & $\begin{array}{l}-0.0237 \\
(0.0866)\end{array}$ & & $\begin{array}{l}-0.1046 \\
(0.0650)\end{array}$ \\
\hline$\beta_{1}$ & $\begin{array}{l}0.7511^{*} \\
(0.1003)\end{array}$ & $\begin{array}{c}-0.7976^{*} \\
(0.2177)\end{array}$ & $\begin{array}{c}0.0267 \\
(0.1871)\end{array}$ & $\begin{array}{c}-0.9342 * \\
(0.0396)\end{array}$ & $\begin{array}{c}0.2097 \\
(0.2338)\end{array}$ & $\begin{array}{c}-0.9222 * \\
(0.0358)\end{array}$ \\
\hline$\gamma$ & $\begin{array}{l}-0.3008^{*} \\
(0.1325)\end{array}$ & $\begin{array}{c}-1.5412 * \\
(0.4712)\end{array}$ & $\begin{array}{c}-0.7073^{*} \\
(0.3484)\end{array}$ & $\begin{array}{c}-1.8288^{*} \\
(0.3930)\end{array}$ & $\begin{array}{c}-0.6497 * * \\
(0.3576)\end{array}$ & $\begin{array}{c}-1.2891^{*} \\
(0.4918)\end{array}$ \\
\hline LR & $\begin{array}{l}5.6393 * \\
{[0.0190]}\end{array}$ & $\begin{array}{c}68.1393^{*} \\
{[0.0000]}\end{array}$ & $\begin{array}{l}9.8291 * \\
{[0.0021]}\end{array}$ & $\begin{array}{c}2385.160^{*} \\
{[0.0000]}\end{array}$ & $\begin{array}{c}3.7939 * * \\
{[0.0534]}\end{array}$ & $\begin{array}{c}2867.248^{*} \\
{[0.0000]}\end{array}$ \\
\hline$L B Q(7)$ & $\begin{array}{c}3.1826 \\
{[0.3643]}\end{array}$ & $\begin{array}{c}2.6424 \\
{[0.4501]}\end{array}$ & $\begin{array}{c}2.1557 \\
{[0.5407]}\end{array}$ & $\begin{array}{c}1.4419 \\
{[0.6957]}\end{array}$ & $\begin{array}{c}3.1449 \\
{[0.3698]}\end{array}$ & $\begin{array}{c}1.5654 \\
{[0.6672]}\end{array}$ \\
\hline$L B Q^{2}(7)$ & $\begin{array}{c}3.9532 \\
{[0.2665]}\end{array}$ & $\begin{array}{c}3.9464 \\
{[0.2673]}\end{array}$ & $\begin{array}{c}6.0527 \\
{[0.1090]}\end{array}$ & $\begin{array}{c}6.1989 \\
{[0.1023]}\end{array}$ & $\begin{array}{c}5.1500 \\
{[0.1611]}\end{array}$ & $\begin{array}{c}4.5761 \\
{[0.2056]}\end{array}$ \\
\hline Skewness & $\begin{array}{c}0.1012 \\
{[0.6222]}\end{array}$ & $\begin{array}{c}0.1188 \\
{[0.5631]}\end{array}$ & $\begin{array}{l}-0.0127 \\
{[0.9504]}\end{array}$ & $\begin{array}{l}-0.0755 \\
{[0.7130]}\end{array}$ & $\begin{array}{l}-0.0471 \\
{[0.8124]}\end{array}$ & $\begin{array}{l}-0.0541 \\
{[0.7850]}\end{array}$ \\
\hline Kurtosis & $\begin{array}{c}0.1401 \\
{[0.7366]}\end{array}$ & $\begin{array}{c}0.2675 \\
{[0.5209]}\end{array}$ & $\begin{array}{c}0.7983 * * \\
{[0.0554]}\end{array}$ & $\begin{array}{c}0.5531 \\
{[0.1845]}\end{array}$ & $\begin{array}{c}0.3509 \\
{[0.3832]}\end{array}$ & $\begin{array}{l}0.7009 * * \\
{[0.0816]}\end{array}$ \\
\hline Normality & $\begin{array}{c}0.3665 \\
{[0.8325]}\end{array}$ & $\begin{array}{c}0.7738 \\
{[0.6791]}\end{array}$ & $\begin{array}{c}3.8543 \\
{[0.1455]}\end{array}$ & $\begin{array}{c}1.9864 \\
{[0.3703]}\end{array}$ & $\begin{array}{c}0.8530 \\
{[0.6527]}\end{array}$ & $\begin{array}{c}3.2491 \\
{[0.1969]}\end{array}$ \\
\hline Function value & -180.8407 & -173.9992 & -176.1105 & -173.5500 & -196.2023 & -195.0376 \\
\hline
\end{tabular}

Note: $\quad$ See Table 7.

* denotes 5-percent significance level.

** denotes 10-percent significance level. 
Table 10: $\quad$ Feedback Model Estimates with Structural Breaks in Mean and Variance Panel A: $\quad$ GARCH(1,1)-M Estimates with Level Effect

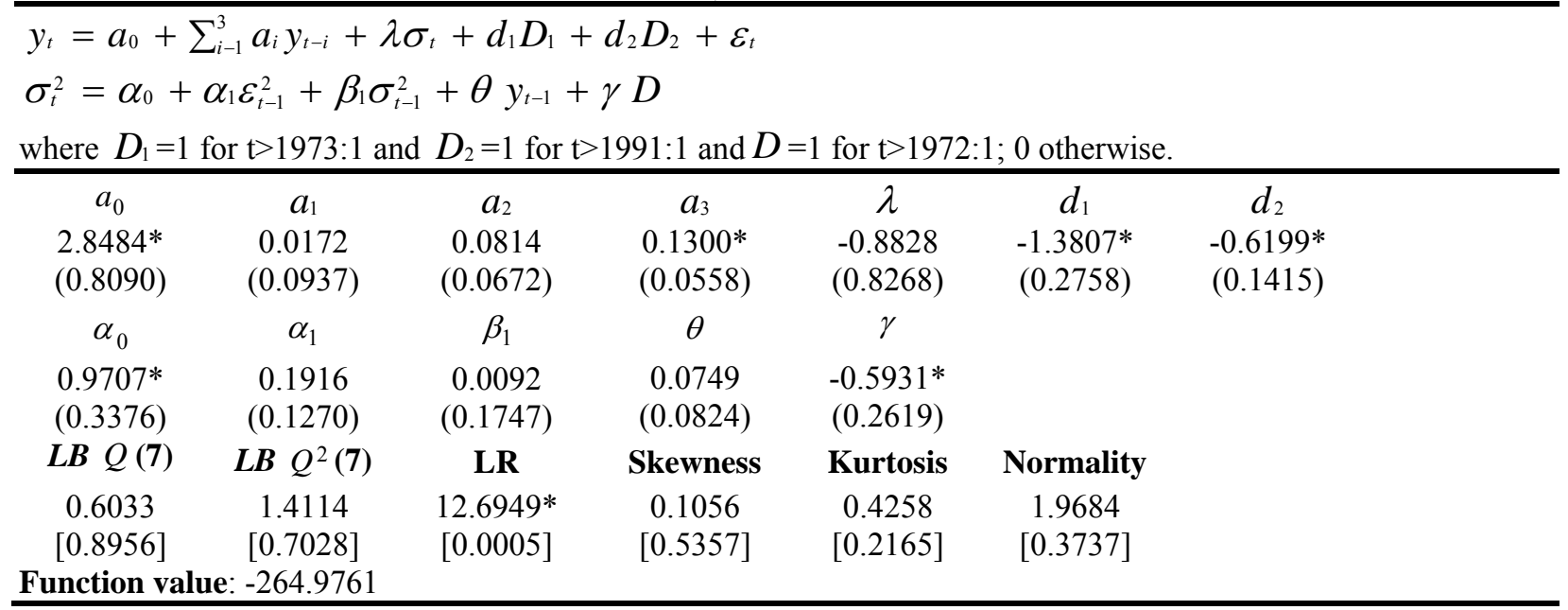

\section{Panel B:}

\begin{tabular}{|c|c|c|c|c|c|}
\hline$a_{0}$ & $a_{3}$ & $\lambda$ & $d_{1}$ & $d_{2}$ & \\
\hline $\begin{array}{l}2.8829 * \\
(0.7618)\end{array}$ & $\begin{array}{l}0.1246^{*} \\
(0.0559)\end{array}$ & $\begin{array}{l}-0.7087 \\
(0.6877)\end{array}$ & $\begin{array}{c}-1.4304 * \\
(0.2882)\end{array}$ & $\begin{array}{c}-0.6879 * \\
(0.1319)\end{array}$ & \\
\hline$\alpha_{0}$ & $\alpha_{1}$ & $\theta$ & $\gamma$ & & \\
\hline $\begin{array}{l}1.0660 * \\
(0.2836)\end{array}$ & $\begin{array}{c}0.1865 \\
(0.1250)\end{array}$ & $\begin{array}{c}0.0529 \\
(0.0779)\end{array}$ & $\begin{array}{c}-0.6694 * \\
(0.2562)\end{array}$ & & \\
\hline$L B Q(7)$ & $\boldsymbol{L} \boldsymbol{B} Q^{2}(7)$ & LR & Skewness & Kurtosis & Normality \\
\hline $\begin{array}{c}2.6950 \\
{[0.4410]}\end{array}$ & $\begin{array}{c}1.9804 \\
{[0.5764]}\end{array}$ & $\begin{array}{c}42.3224 * \\
{[0.0000]}\end{array}$ & $\begin{array}{c}0.1063 \\
{[0.5331]}\end{array}$ & $\begin{array}{c}0.5399 \\
{[0.1171]}\end{array}$ & $\begin{array}{c}2.9325 \\
{[0.2307]}\end{array}$ \\
\hline
\end{tabular}

Function value: -265.7821

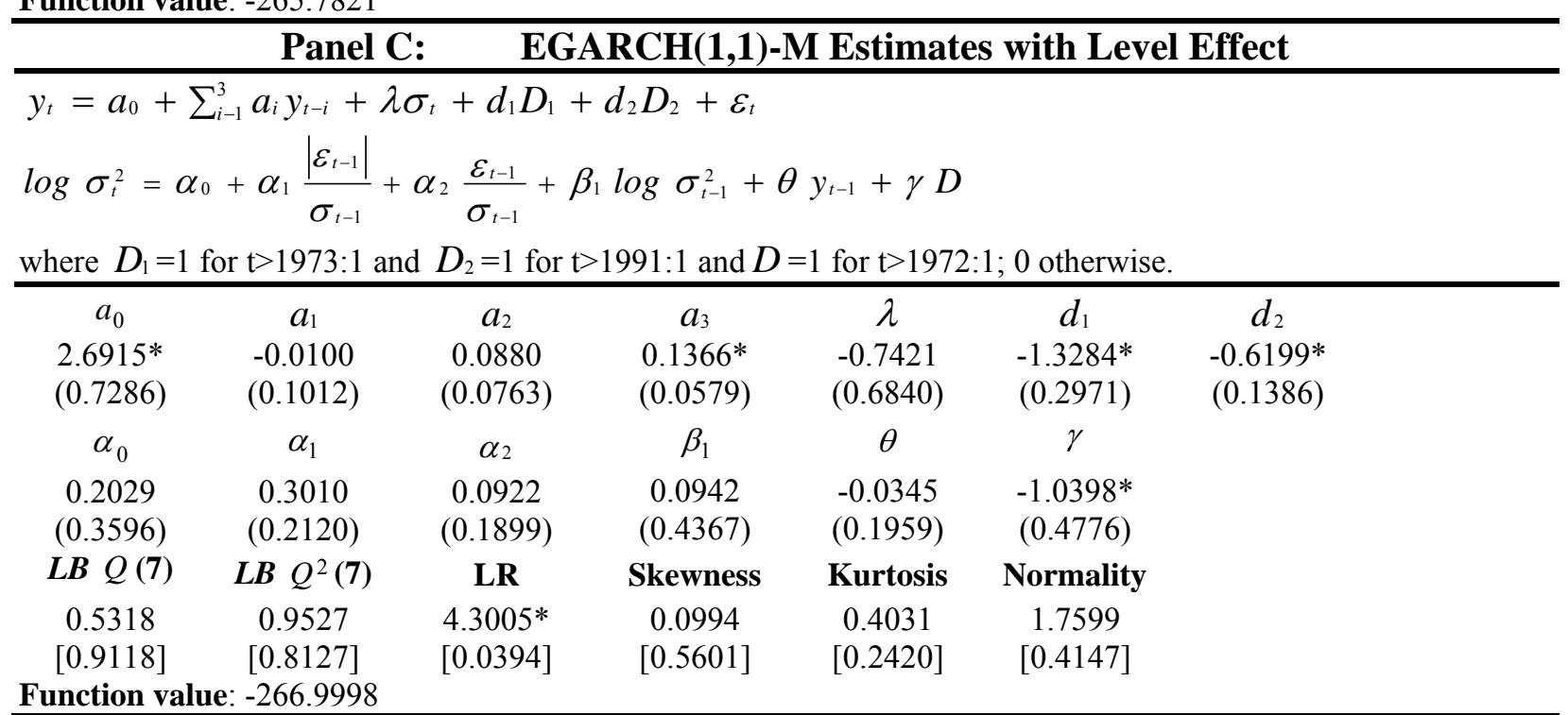

Note: $\quad$ See Table 7 . The coefficients $\lambda$ and $\theta$ correspond to the standard deviation in the mean equation and the level effect in the variance equation, respectively.

* denotes 5-percent significance level.

** denotes 10 -percent significance level. 


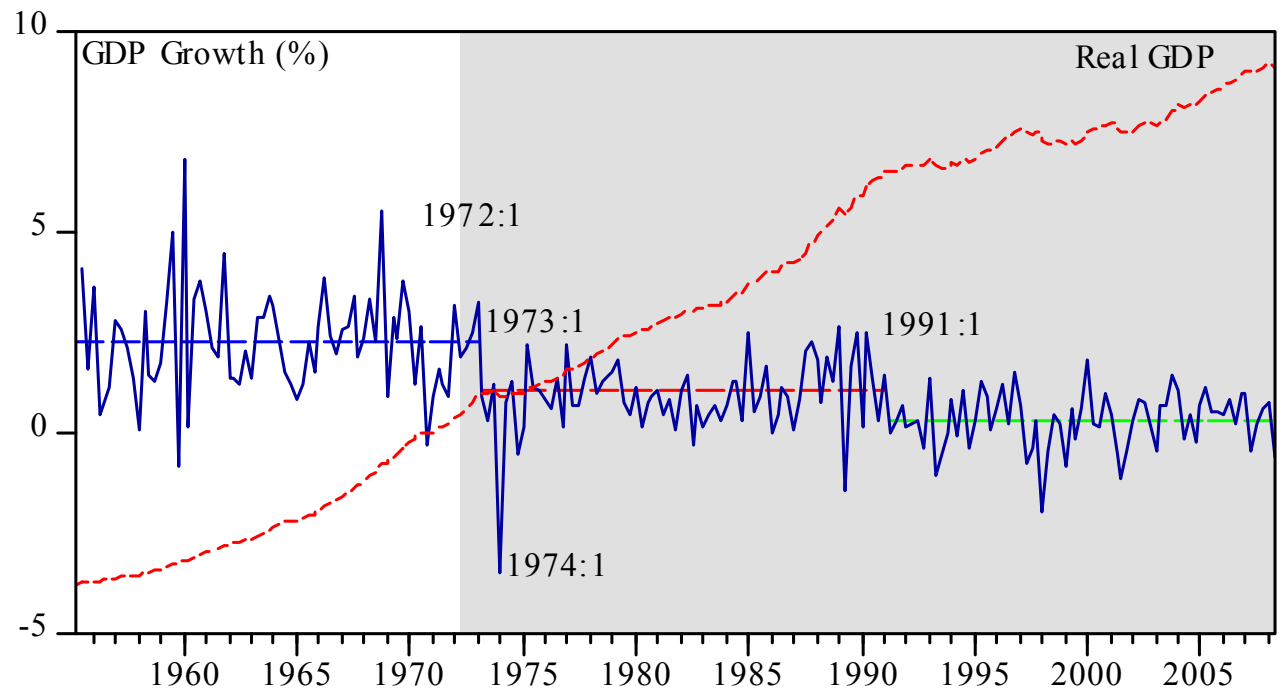

Figure 1. Real GDP Growth Rate and Structural Break 